\title{
REVISIÓN SISTEMÁTICA DE PROGRAMAS DE INTERVENCIÓN CON MENORES EN RIESGO DE EXCLUSIÓN SOCIAL
}

\section{TRABAJO DE FIN DE MÁSTER}

\author{
Autor/a: Sara Huelin Zaragoza \\ Tutor/as: M. ${ }^{\mathrm{a}}$ del Mar Ortiz Gómez \\ Inmaculada Alemany Arrebola
}

Máster en Diversidad Cultural. Un enfoque multidisciplinar y fronterizo

Especialidad: Educación

Septiembre, 2020 


\section{DECLARACIÓN DE ORIGINALIDAD}

Melilla, a 14 de septiembre de 2020

D./D. a Sara Huelin Zaragoza con DNI no 45317788-Z, alumno/a del Máster Universitario en Diversidad Cultural. Un enfoque multidisciplinar $y$ transfronterizo garantiza, al firmar este Trabajo Fin de Máster, que este trabajo ha sido realizando respetando los derechos de otros autores a ser citados, cuando se han utilizado sus materiales, resultados o publicaciones.

EL ALUMNO

Fdo.: 


\section{ÍNDICE}

\section{RESUMEN}

ABSTRACT

1. INTRODUCCIÓN

2. MARCO TEÓRICO

2.1. Definiciones

2.1.1 Programas de intervención

2.2. Características y perfiles de los colectivos en riesgo y/o situación de exclusión social

2.3. Indicadores de riesgo

3. OBJETIVOS

4. MÉTODO

4.1. Formulación del problema

4.2. Procedimiento de búsqueda

4.3. Codificación de los estudios

5. RESULTADOS Y DISCUSIÓN

6. CONCLUSIONES 


\section{RESUMEN}

El presente Trabajo Fin de Máster consiste en una revisión sistemática de programas de intervención con menores en riesgo de exclusión social, cuyos objetivos son: 1) Analizar las investigaciones que estudian la situación de los menores en riesgo de exclusión social y los factores más estudiados y 2) Evaluar los programas de intervención llevados a cabo con menores en riesgo de exclusión social. Para ello se llevó a cabo una búsqueda bibliográfica en las bases de datos Google Académico, Dialnet, Digibug y Scielo, introduciendo la ecuación de palabras clave: [(“programas de intervención” $\mathrm{O}$ "programas de prevención”) Y ("exclusión social" $\mathrm{O}$ "MENA" $\mathrm{O}$ "inclusión social" $\mathrm{O}$ "menores en riesgo" O "minoría étnica" O "riesgo de exclusión social")]. De las 107 entradas encontradas para alcanzar el primer objetivo, solo 9 de estas cumplían con todos los criterios de inclusión, mientras que de las 74497 entradas encontradas para conseguir el segundo objetivo, fueron 7 las que cumplían con los mismos. Uno de los criterios que la gran mayoría no cumplía era que estos programas de intervención hubieran sido ejecutados. Una vez seleccionados los estudios de veraz relevancia, se procedió a extraer los datos más relevantes para ambos objetivos (autores de los estudios, año y lugar de publicación, título del estudio o programa, objetivos, tamaño de la muestra, instrumentos de evaluación de los programas de intervención, conclusiones o resultados más relevantes), recogidos en dos tablas. Las conclusiones obtenidas tras el análisis de estas investigaciones responden a la formulación del problema, ¿Qué variables sociodemográficas son las más estudiadas en menores en riesgo de exclusión social? ¿Cuáles son las variables predictoras que pueden ayudar a poner en marcha programas de intervención? ¿Cuáles son los contextos de intervención más frecuentes en los que se trabaja con esta población? ¿Cómo han funcionado los programas desarrollados?

Se pone fin a esta revisión sistemática con la idea final de la necesidad de destinar recursos económicos y materiales así como desarrollar políticas sociales que vayan encaminadas a diseñar e implementar programas integrales que ayuden a la infancia a superar los problemas que conlleva las situaciones de pobreza y/o exclusión social. 
Palabras clave: Menores, exclusión social, MENA, programas de intervención, pobreza infantil, vulnerabilidad y minoría étnica.

\section{ABSTRACT}

This Master's Thesis consists of a systematic review of intervention programs with minors at risk of social exclusion, the objectives of which are: 1) To analyze the research that studies the situation of minors at risk of social exclusion and the most studied factors and 2) Evaluate the intervention programs carried out with minors at risk of social exclusion. For this, a bibliographic search was carried out in the Google Academic, Dialnet, Digibug and Scielo databases, introducing the equation of keywords: [("intervention programs" OR "prevention programs") AND ("social exclusion" OR "MENA" OR "social inclusion" OR "minors at risk" OR "ethnic minority" OR "risk of social exclusion")]. Of the 107 entries found to achieve the first objective, only 9 of these met all inclusion criteria, while of the 74,497 entries found to achieve the second objective, 7 were those that met all themselves. One of the criteria that the vast majority did not meet was that these intervention programs had been implemented. Once the studies of true relevance had been selected, we proceeded to extract the most relevant data for both objectives (authors of the studies, year and place of publication, title of the study or program, objectives, conclusions or most relevant results, sample size, and the instruments for evaluating intervention programs), collected in two tables. The conclusions obtained after the analysis of these investigations respond to the formulation of the problem, which sociodemographic variables are the most studied in minors at risk of social exclusion? What are the predictor variables that can help implement intervention programs? What are the most frequent intervention contexts in which we work with this population? How have the developed programs worked?

This systematic review ends with the final idea of the need to allocate economic and material resources as well as to develop social policies that are aimed at designing and implementing comprehensive programs that help children to overcome the problems that situations of poverty and poverty entail. / or social exclusion. 
Keywords: Minors, social exclusion, MENA, intervention programs, child poverty, vulnerability and ethnic minority.

\section{REVISIÓN SISTEMÁTICA DE PROGRAMAS DE INTERVENCIÓN CON MENORES EN RIESGO DE EXCLUSIÓN SOCIAL}

El presente trabajo consiste en una revisión sistemática de los diversos programas de intervención con menores en riesgo de exclusión social, al ser imprescindible este paso antes de iniciar cualquier actuación.

Se ha encontrado un gran número de entradas en las diferentes plataformas de búsqueda, utilizando los temas seleccionados para dicha revisión sistemática. Sin embargo, se han repetido muchas de ellas en las diferentes bases, además de haber tenido que descartar muchas otras puesto que no cumplían con los criterios de inclusión seleccionados, tal y como se verá más adelante.

Por otro lado, cabe destacar la gran necesidad de implantar e innovar estos programas de intervención debido al fuerte crecimiento de los colectivos en riesgo de exclusión social en nuestro país, así como la falta de programas actuales que muestren su efectividad, como se ha podido constatar a lo largo de la realización de dicho trabajo.

\section{INTRODUCCIÓN}

La sociedad en la que nos encontramos actualmente está en constante cambio, lo cual puede llegar a causar desafíos y problemas a los que algunas familias y grupos de menores deben enfrentarse y, en ciertas ocasiones, esta situación puede resultar más complicada si el colectivo mencionado se encuentra en una situación socioeconómica condicionada por una especial dificultad, o en situación de riesgo de exclusión y/o marginación social, desestructuración familiar... llevando esto a una vulnerabilidad mayor para estas familias o grupos de menores.

Estas dificultades y necesidades observables en ciertos colectivos deben ser abordadas por diferentes competencias, instituciones, profesionales... y en diferentes niveles o ámbitos 
(social, emocional, familiar, afectivo, educativo, material, etc.). Sin embargo, las posibilidades que ofrece la sociedad no siempre se ajustan a las necesidades de todos estos niños, adolescentes y familias, especialmente a aquellos que presentan mayores dificultades en sus procesos de socialización e integración. Los centros educativos encuentran, en numerosas ocasiones, obstáculos o limitaciones para llevar a cabo actuaciones de seguimiento y de atención a la diversidad, los cuales pueden dar respuesta a las diferentes necesidades y urgencias de estos menores.

Por estos motivos se ve la necesidad urgente de investigar acerca de diferentes programas, como los ofertados en los Centros de Día, Centros de acogida, Centros de Enseñanza Secundaria... con el objetivo de que las carencias que presentan estos colectivos puedan ser solventadas desde un amplio abanico de posibilidades. Es por ello que algunos programas son insuficientes al arrancar a la persona de su entorno natural, para así intentar integrarlo en la sociedad, lo cual parece algo contradictorio. Por esto, se han analizado diferentes programas, de los cuales algunos sí se consideran mejor enfocados a que el menor en riesgo de exclusión o marginación social permanezca en su entorno natural, protegiéndole a través de acciones de prevención, capacitación e integración, posibilitando una reducción de los desajustes. Por tanto, este trabajo pretende estudiar, especialmente, aquellos programas que pretenden mejorar el desarrollo armónico, a nivel físico, mental, saludable y educativo, en menores y sus familias, mediante la realización de acciones preventivas, ofreciendo una multitud de actividades tanto de ocio como educativas.

\section{MARCO TEÓRICO}

A continuación, se presentan aquellos conceptos que se consideran más relevantes en el tema tratado, como es la exclusión social, marginación, programas de intervención, características de las personas catalogadas en riesgo de exclusión social... para concretar un punto de partida.

\subsection{Definiciones}

El término de exclusión social puede denominarse de diversas maneras, como: inadaptación social, conflicto social, marginación... Con todos estos términos se define a personas o colectivos con fuertes carencias, o colectivos "no normalizados", que presentan 
situaciones con disfunciones, impidiéndoles integrarse o desarrollarse con total normalidad en su medio natural (Sánchez Ramos, 2011).

Ballester y Figuera (2000: 289) lo definen como "un proceso multicausal, caracterizado por situaciones o circunstancias concretas, originadas por el interaccionismo contextual, el cual provoca cierta vulnerabilidad social, produciéndose una incapacidad para acceder a determinados recursos que permitirían la integración y la participación en la sociedad, convertido en ciudadano de derechos y obligaciones".

Se podría resumir esta definición de exclusión social, según Sánchez Ramos (2011: 34), con una frase muy conocida: "quiero, pero no puedo". La exclusión social muchas veces es exactamente eso, un querer y no poder.

Por otro lado, el término de "marginación social" haría referencia a estar al margen de la sociedad, con la particularidad de que en ciertos casos ésta es impuesta y en otros, no.

Según Valverde (1993:22), marginal se refiere, con respecto a un grupo, a todo aquel individuo que de una forma u otra, por algún motivo, y en un área más o menos concreta, se encuentra situado al margen de la "normalidad" de ese grupo. Por lo tanto, se es marginado cuando no se está dentro de ese "grupo normativo". Esto hace que, de una forma u otra, uno elija encontrarse en esa postura de marginalidad, puesto que los valores y límites de lo que se corresponde con la "normalidad", y lo que no, ya viene impuesto.

Algunos ejemplos de grupos marginados podrían ser:

- Ancianos, niños y adolescentes, personas con discapacidad, enfermos, los cuales podrían ser marginados, no por la sociedad, sino por el mercado, al no ser sujetos productivos.

- En cuanto al ámbito de la represión de conductas, se podrían ubicar a prostitutas, drogadictos, alcohólicos, delincuentes, que también podrían ser marginados.

- La falta de recursos, como pueden ser vagabundos, mendigos, parados de larga duración, personas sin hogar, etc.

- También se podría dar una automarginación, como en los casos de los grupos hippies o revolucionarios sociales, que no comparten las ideas imperantes, y buscan una satisfacción de necesidades que los sitúan fuera del grupo normativo anteriormente mencionado. 
Por otro lado, y según el Marco de la Unión Europea (UE), la inclusión social se ha definido como un proceso que asegura que aquellas personas en riesgo de pobreza y de exclusión social aumenten las oportunidades y los recursos necesarios para participar completamente en la vida económica, social y cultural, así como gozar de unas condiciones de vida y de bienestar que se consideran normales en la sociedad en la que viven (Ministerio de Sanidad, Consumo y Bienestar Social, 2019).

\subsubsection{Programas de intervención}

En cuanto al concepto de programa, según De Miguel (2000: 186), haría referencia a "todo plan, proyecto o servicio mediante el cual se diseña, organiza y pone en práctica un conjunto de acciones dirigidas a la consecución de unas metas". Pérez Juste (2006:405) aporta otro concepto de programa y lo define como "un plan intencional y sistemático de acción, específica y expresamente desarrollado para servir a un grupo de metas y objetivos de calidad, tendentes a resolver una situación problemática o a mejorar una necesidad, basándose en la evaluación inicial de necesidades, dirigido a atender a personas y grupos en un contexto determinado, debiendo estar fundamentado en teorías y modelos que han demostrado que ayudan a solucionar determinados problemas mediante los procedimientos que el programa aplica".

En referencia a los tipos de programas, el presente trabajo destacará los de intervención, que se definen como el conjunto de acciones sistemáticas, planificadas, basadas en necesidades identificadas y orientadas a unas metas, como respuesta a esas necesidades, con una teoría que lo sustente (Rodríguez Espinar, Álvarez, Echeverría y Marín 1993).

Un programa o proyecto necesita poseer una serie de características para que este sea considerado de intervención, como serían el análisis y diagnóstico de necesidades, planteamiento de objetivos claros y concisos, establecimiento de contenidos, contexto y destinatarios, así como las funciones y agentes de intervención y evaluación de dicho programa o proyecto. Otra de las finalidades de los programas es la prevención, entendida como el proceder por el desarrollo global de una comunidad específica, por medio de las condiciones de vida que pueden estar favoreciendo la aparición de problemas sociales. El propósito es evitar la aparición de riesgos que afecten a la persona o bien disminuir sus efectos. Es muy importante conocer el motivo que conlleva a las personas a realizar dichos comportamientos. Pueden ser motivados por una decisión personal, pero, en el caso de los 
menores, puede ser provocado por la presión social, es decir, bien por identidad del grupo, intimidación o chantaje, o para sentirse aceptado socialmente en un grupo (Martínez Iglesias, 2016).

\subsection{Características y perfiles de los colectivos en riesgo y/o situación de exclusión} social

En cuanto a las características de las situaciones en las que se prescribe que una persona o colectivo se encuentra en situación de riesgo y/o exclusión social, según Room (1997:123), estarían aquellas que: “(1) sufren desventajas generalizadas en términos de educación, habilidades, empleo, vivienda, recursos financieros, etc.; (2) sus oportunidades de obtener acceso a las principales instituciones que distribuyen esas oportunidades de vida son sustancialmente menores que las del resto de la población; (3) esas desventajas y accesos disminuidos persisten a lo largo del tiempo".

Si se concretan los perfiles de estos colectivos a los niños y adolescentes, se identifican con las siguientes características, según la Asociación Cultural Norte Joven (2000):

- Procedentes de familias desestructuradas con muy bajos niveles socioculturales y económicos (abandono/ sobreprotección).

- Historial recurrente de fracaso escolar (y muchas veces personal) que incide en su autoestima y su motivación.

- Con indefensión aprendida (para enfrentarse al aprendizaje, a las relaciones interpersonales, a la búsqueda de empleo y, en general, al mundo adulto).

- Sin habilidades para el «éxito» (poca motivación de logro, baja resistencia a la frustración, poco control de las situaciones, etc.).

- Escasa oportunidad de aprender los patrones básicos de comportamiento social adoptado.

- Con desventaja sociocultural sostenida, patrones de relación familiar inadecuados y subdesarrollo de capacidades básicas.

- No han tenido modelos de comportamiento adecuado (social, laboral, etc.).

- Con preconcepciones negativas sobre el trabajo y los empresarios (trabajo =explotación y aburrimiento).

- «Educados/as» en la calle (roles sociales agresivos, ley del más fuerte, etc.). 
- Con experiencias de consumo de alcohol y/o drogas.

- Aumentan los jóvenes excluidos pertenecientes a minorías étnicas o culturales (inmigrantes, cultura gitana).

\subsection{Indicadores de riesgo}

A priori, y de forma general, se podrían citar diversos indicadores de riesgo relacionados con el entorno social y educativo del menor, en los que influyen ciertas competencias emocionales, así como estrategias de regulación de emociones, en las que se debe incidir (se explicarán en la parte de metodología del presente trabajo), siendo estos indicadores: conductas disruptivas, comunicación agresiva, carencias en el control de impulsos, bullying (rol de agresores), vandalismo, iniciación en comportamientos delictivos (hurtos, menudeo, etc).

A la hora de explicar los indicadores de riesgo para el colectivo de menores, en relación a la exclusión social, cabe mencionar la aportación de Montraveta (cit. en Mondragón y Trigueros, 2004:59), representada en la Figura 1, donde si el menor se caracteriza con algunas de esas situaciones, se estará ante un indicador de riesgo. 


\begin{tabular}{|c|c|c|}
\hline $\begin{array}{l}\text { Menores maltratados física o } \\
\text { psíquicamente } \\
\text { Menores abandonados por ambos } \\
\text { progenitores } \\
\text { Menores desescolarizados y/o } \\
\text { falta de rendimiento escolar. } \\
\text { Menores con bloqueo de } \\
\text { aprendizajes que no se deriva de } \\
\text { sus limitaciones intelectuales } \\
\text { congénitas o traumáticas. } \\
\text { Trabajo prematuro del menor. } \\
\text { Menores con desnutrición o falta } \\
\text { de higiene importante. } \\
\text { Menores con carencias afectivas. } \\
\text { Menores drogodependientes. } \\
\text { Menores rebeldes. }\end{array}$ & $\begin{array}{l}\text { Incultura de los progenitores. } \\
\text { Familias con algún hijo } \\
\text { institucionalizado } \\
\text { Familias con algún progenitor con } \\
\text { enfermedad mental grave, } \\
\text { drogodependiente o alcohólico. } \\
\text { Familias con algún progenitor en la } \\
\text { cárcel o delincuente. } \\
\text { Familias con un solo adulto, con } \\
\text { dificultades económicas } \\
\text { importantes o dificultades por el } \\
\text { tipo de trabajo del progenitor. } \\
\text { Desadaptación laboral y social de } \\
\text { los padres. } \\
\text { Familias numerosas con } \\
\text { dificultades económicas } \\
\text { importantes. } \\
\text { Edad avanzada de los padres. }\end{array}$ & $\begin{array}{l}\text { Entorno social con imágenes } \\
\text { identificativas no deseables: pocos o } \\
\text { nulos equipamientos sociales y falta } \\
\text { de servicios de tiempo libre de } \\
\text { niños/as y adolescentes. } \\
\text { Superpoblación. } \\
\text { Viviendas reducidas. Hacinamiento. } \\
\text { Presencia de grupos de adolescentes } \\
\text { incontrolados en las calles } \\
\text { Sin servicios escolares suficientes o } \\
\text { deficitarios y falta de facilidades } \\
\text { para estudios de formación } \\
\text { profesional u otros. } \\
\text { Medio que rechaza al menor por sus } \\
\text { características: } \\
\text { intolerancia, actitudes agresivas o } \\
\text { represivas... }\end{array}$ \\
\hline
\end{tabular}

Figura 1. Indicadores de riesgo para la exclusión social. Fuente: Montraveta, citado en Mondragón y Trigueros (2004: 59).

\section{OBJETIVOS}

Los colectivos en riesgo de exclusión social y/o vulnerabilidad se han incrementado en los últimos años, ya sea por el nivel socio-económico, la situación geográfica en la que se resida, la migración, la discriminación en cualquier ámbito como por ejemplo, el género, origen étnico, pobreza... Esto hace necesario revisar los medios e instrumentos existentes para poder combatirlo, por lo tanto, esta revisión tendrá en cuenta tanto los estudios que analizan esta realidad tan cruel, como los programas de intervención destinados a estos colectivos y, más concretamente, a los más vulnerables como son los menores.

Por todo lo mencionado anteriormente, los objetivos planteados en esta revisión sistemática son:

- Analizar las investigaciones que estudian la situación de los menores en riesgo de exclusión social y los factores más estudiados.

- Evaluar los programas de intervención llevados a cabo con menores en riesgo de exclusión social. 


\section{MÉTODO}

En esta investigación se han incluido las principales secciones de una revisión sistemática (sin meta-análisis), de la declaración PRISMA (Moher et al., 2015; PeresteloPérez, 2013; Urrutia y Bonfill, 2010).

\subsection{Formulación del problema}

Las preguntas planteadas a lo largo de esta revisión sistemática son:

1) ¿Qué variables sociodemográficas son las más estudiadas en menores en riesgo de exclusión social?

2) ¿Cuáles son las variables predictoras que pueden ayudar a poner en marcha programas de intervención?

3) ¿Cuáles son los contextos de intervención más frecuentes en los que se trabaja con esta población en riesgo de exclusión social?

4) ¿Cómo han funcionado los programas desarrollados?

\subsection{Procedimiento de búsqueda}

Para llevar a cabo el procedimiento de búsqueda, se han seleccionado plataformas de búsqueda de información como Dialnet, Google Académico, Scielo y Digibug. Las entradas que se han recogido a lo largo de todo el proceso de búsqueda han sido tesis doctorales, Trabajos fin de Máster, Trabajos Fin de Grado, artículos científicos, libros y artículos de libros. Puesto que analizar y evaluar los programas de intervención no es el único objetivo planteado, sino que además, se va a estudiar la situación de este colectivo desfavorecido en diferentes ámbitos, y se van a examinar diferentes programas consultados, los documentos que se quieren obtener no sólo tienen que ser programas de intervención propiamente dichos, sino todos aquellos que enriquezcan el conocimiento de este objeto de estudio.

Una vez determinado dónde y qué es lo que se quiere investigar, se debe acordar una serie de criterios de inclusión y de exclusión, así como los temas que se introducirán en la búsqueda de información, acorde a estos criterios, con el fin de tener un mejor acierto en los documentos que se encuentren, agrupando y sintetizando mejor dicha información. 
Para la selección de los primeros documentos relevantes para el estudio, se empleó la siguiente ecuación de búsqueda en los campos título, resumen y palabras claves, a través de su combinación entre intersecciones y uniones de los operadores " $\mathrm{O}$ " e "Y", con el fin de seleccionar conjuntos de datos específicos: [("programas de intervención” O "programas de prevención") Y ("exclusión social” O "MENA" O "inclusión social” O "menores en riesgo" $\mathrm{O}$ “minoría étnica" $\mathrm{O}$ "riesgo de exclusión social”)].

Las búsquedas se han realizado introduciendo cada ecuación que se ha formulado, en las distintas plataformas ya mencionadas que, a su vez, se han clasificado según el tipo de documento al que pertenecen. Tras los resultados obtenidos, se ha efectuado un cribado teniendo en cuenta aspectos como el año de publicación, el número de la muestra, el colectivo al que va dirigido, el objetivo y los aspectos en los que incide el programa de intervención, etc. Además, se han tenido en cuenta los programas repetidos, para tener un número exacto de documentos centrados adecuadamente en el objeto de investigación. Los criterios de inclusión seleccionados se resumen en los siguientes: 
1. Los documentos buscados deben referirse y centrarse en programas de intervención.

2. Estos programas de intervención deben ir destinados a un determinado colectivo, siendo este aquellos que estén formados por jóvenes, adolescentes, estudiantes y menores de edad. Sin embargo, no será excluyente si este grupo se trata de familias en las que convivan menores.

3. Las investigaciones deben tratarse de trabajos realizados en el ámbito nacional, perteneciendo todos estos a España, con el fin de contextualizar dichas investigaciones y conocer cuáles han sido los trabajos elaborados en nuestro país.

4. Estos colectivos han de ser personas en situación de exclusión social, pertenecer a minorías étnicas o ser menores no acompañados.

5. El tamaño de la muestra de los programas de intervención tiene que superar los 12 sujetos.

6. El año de publicación de los documentos que recogen estos programas será posterior al año 2014.

Por otro lado, las plataformas o bases consultadas para la obtención de información y estudios, son las siguientes:

Dialnet

https://dialnet.unirioja.es/

Digibug $\quad$ https://digibug.ugr.es/

Scielo

https://scielo.org/es/

Google Académico

https://scholar.google.com/schhp?hl=es

Figura 2. Fuentes consultadas para la elaboración de la revisión sistemática. 
Para alcanzar contenidos más veraces y exactos, y una vez pasado el cribado que se ha descrito anteriormente, se han leído y analizado los resúmenes de los documentos que han conseguido llegar hasta esta fase con el fin de decidir si se incluyen o se descartan.

En primer lugar, se realizó la búsqueda de documentos para el primer objetivo de esta revisión sistemática, como es el de revisar los estudios que profundicen sobre la situación de este colectivo en riesgo de exclusión social, tal y como queda reflejado en la Figura 3:

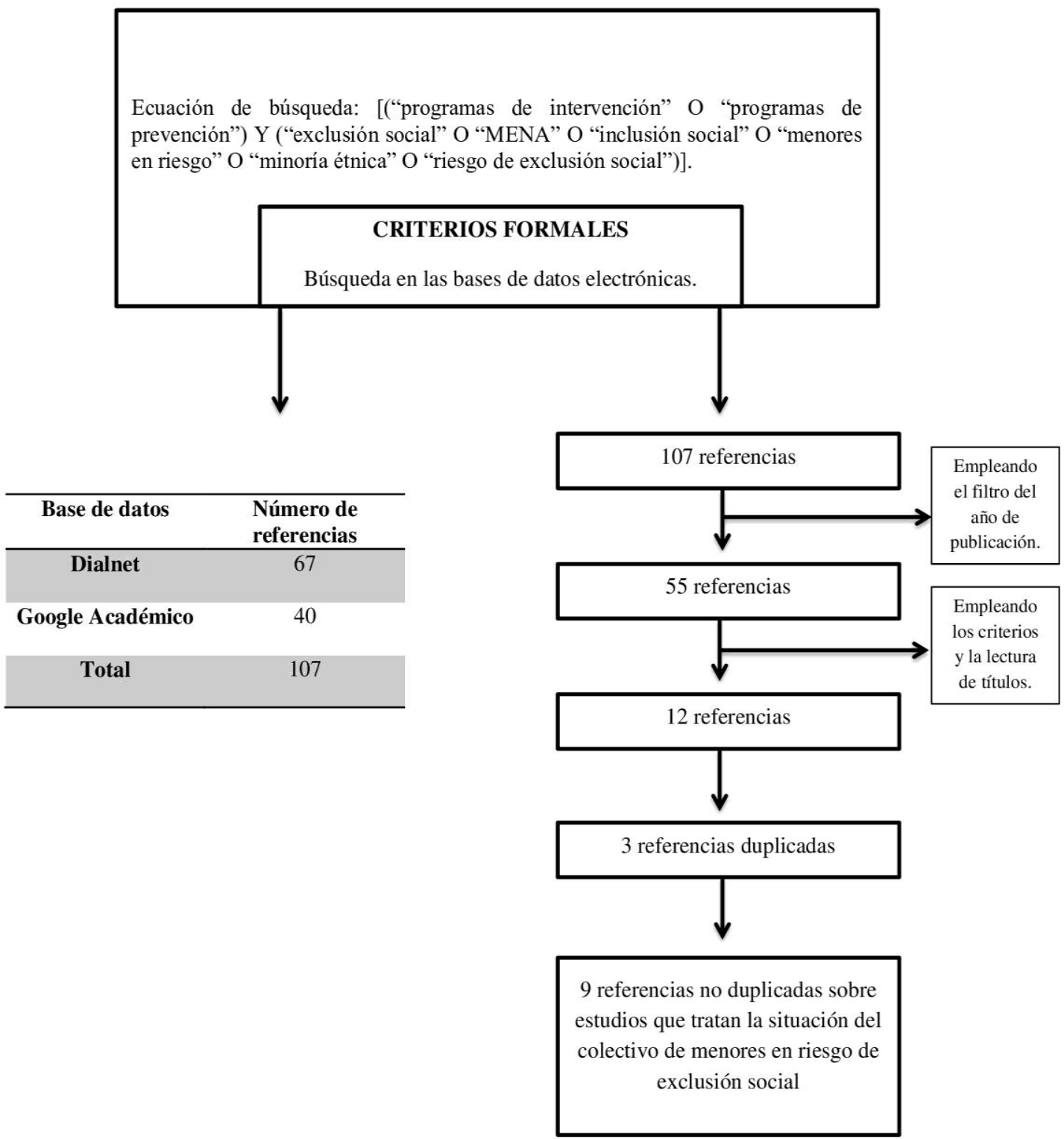

Figura 3. Secuencia del procedimiento de búsqueda y selección de estudios sobre la situación de vulnerabilidad de los menores. 
Por otro lado, se realizó la búsqueda de documentos para el segundo objetivo de esta revisión sistemática, como es el de analizar los programas de intervención con menores en riesgo de exclusión social, tal y como se muestra en la figura 4:

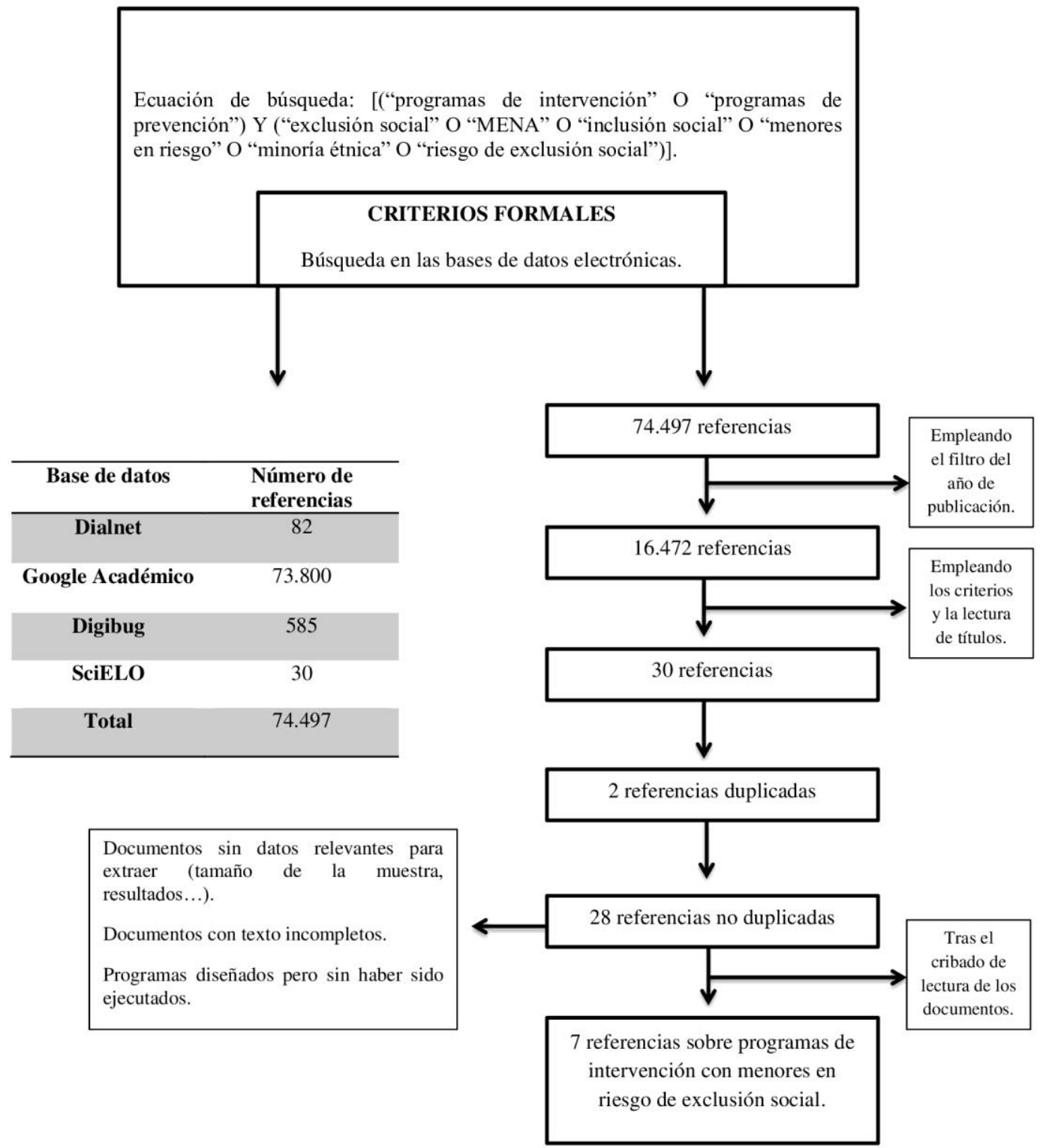

Figura 4. Secuencia del procedimiento de búsqueda y selección de estudios sobre los programas de intervención con menores en riesgo de exclusión social. 
Para poner fin a este apartado, se detalla mediante la siguiente figura, los pasos que se han seguido en el procedimiento de búsqueda de información.

\section{Formulación de objetivos.}

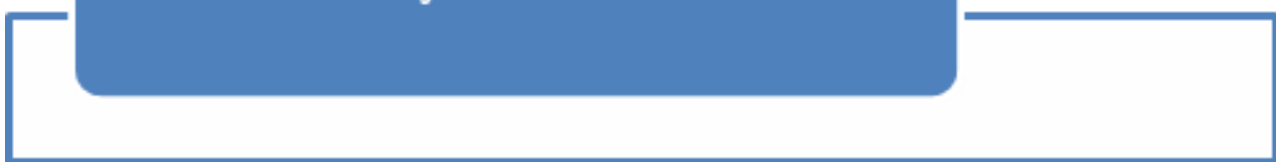

\section{Selección de las bases de datos.}

\section{filtros según los criterios de inclusión.}

Búsqueda propiamente dicha, aplicando los

Selección de los documentos que cumplan los

criterios de inclusión y eliminación de duplicados.

\section{Análisis de los documentos seleccionados.}

Figura 5. Pasos seguidos en el procedimiento de búsqueda de información y estudios.

\subsection{Codificación de los estudios}

Una vez seleccionados los estudios considerados como idóneos para llevar a cabo esta revisión sistemática, y en función del objetivo que se quiera alcanzar de esta revisión, se extrajo y sintetizó los datos relevantes elaborando una tabla en la que se incluye la siguiente información: autor/es, año de publicación, lugar, nombre del programa, los objetivos y las conclusiones. En la Tabla 1 se detalla cada uno de estos apartados y las contribuciones de los artículos encontrados para dar respuesta al primer objetivo. 


\section{UNIVERSIDAD}

DE GRANADA

\section{(3)}

Tabla 1.

Revisión de estudios centrados en el análisis de la situación del colectivo en riesgo de exclusión social.

Autor Año Lugar $\begin{gathered}\text { Nombre del } \\ \text { estudio }\end{gathered} \quad$ Objetivos

\begin{tabular}{|c|c|c|c|c|c|}
\hline $\begin{array}{l}\text { Alonso } \\
\text { Bello, } \\
\text { Santana } \\
\text { Vega y } \\
\text { Feliciano } \\
\text { García }\end{array}$ & 2020 & $\begin{array}{l}\text { Tenerife, } \\
\text { España }\end{array}$ & $\begin{array}{l}\text { Competencias de } \\
\text { empleabilidad de } \\
\text { menores } \\
\text { inmigrantes no } \\
\text { acompañados en } \\
\text { Canarias }\end{array}$ & $\begin{array}{l}\text { Analizar cómo ciertas experiencias de vida pueden } \\
\text { influir en la integración laboral y en la } \\
\text { independencia de los MENA que abandonan el } \\
\text { sistema de protección } \\
\text { Analizar las necesidades de los MENA en su } \\
\text { transición a la edad adulta }\end{array}$ & $\begin{array}{l}\text { Las necesidades, que presentan los menores extranjeros no acompañados en este } \\
\text { estudio, son influyentes a la hora de conseguir su emancipación, así como sus carencias } \\
\text { en estrategias de búsqueda de empleo. Estos tienen un sentimiento de impotencia } \\
\text { debido a la falta de conocimiento tanto de la lengua, como de la cultura de la sociedad } \\
\text { que los acogen, lo que también dificulta la adquisición de un trabajo. Sin embargo, sus } \\
\text { familias, aún en la distancia, constituyen un elemento fundamental a la hora de } \\
\text { conseguir la motivación para buscar empleo y seguir con los estudios. Estos menores } \\
\text { inmigrantes les otorga un gran valor a su formación, con el fin de conseguir un empleo } \\
\text { de forma rápida y mejorar la economía familiar tan precaria que presentan, y mejorar } \\
\text { sus posibilidades de inserción social y laboral. Por lo tanto, se concluye con la gran } \\
\text { necesidad de implementar programas sociales y educativos. }\end{array}$ \\
\hline $\begin{array}{l}\text { Caparrós } \\
\text { y Gelaber }\end{array}$ & 2015 & España & $\begin{array}{lr}\text { Pobreza } & \text { y } \\
\text { vulneración de } \\
\text { los derechos en } \\
\text { la infancia }\end{array}$ & Visibilizar la pobreza infantil & $\begin{array}{l}\text { Se puede concluir que la pobreza infantil se ha convertido en un problema mundial, } \\
\text { afectando tanto a países pobres como ricos, teniendo como consecuencia un } \\
\text { empobrecimiento global agravado por el desmantelamiento de los sistemas de } \\
\text { protección social, a lo que se suma el claro indicio de que estamos inmersos en un } \\
\text { sistema económico que no hace más que generar pobreza y exclusión social. }\end{array}$ \\
\hline $\begin{array}{l}\text { Fenoy } \\
\text { Santiago }\end{array}$ & 2018 & $\begin{array}{l}\text { Sevilla, } \\
\text { España }\end{array}$ & $\begin{array}{l}\text { Fracaso, } \\
\text { absentismo y } \\
\text { abandono } \\
\text { escolar en zonas } \\
\text { en riesgo de } \\
\text { exclusión social: } \\
\text { el caso del IES } \\
\text { Sevilla en } \\
\text { Polígono Sur }\end{array}$ & $\begin{array}{l}\text { Conocer las estrategias de prevención del fracaso, } \\
\text { absentismo y del abandono escolar desarrollado por } \\
\text { parte del IES Sevilla localizado en una zona en } \\
\text { riesgo de exclusión social }\end{array}$ & $\begin{array}{l}\text { Una gran parte del alumnado presenta un absentismo consentido por sus padres, sin } \\
\text { embargo en los resultados se muestra que los alumnos le dan valor a los estudios y desean } \\
\text { continuar estudiando. Como estrategias de prevención del fracaso, absentismo y abandono } \\
\text { escolar, este IES intenta mejorar el rendimiento académico mandando al alumnado tareas } \\
\text { para casa y reforzando estas conductas, utilizan la comunicación positiva como estrategia } \\
\text { cuando los discentes faltan a clase. Para el refuerzo positivo de la asistencia, se dan "partes } \\
\text { verdes"cuando estos asisten a clase, que pueden canjear por un incremento de la nota. Otra } \\
\text { de sus estrategias consiste en mejorar la participación de las familias, puesto que estas no se } \\
\text { involucran. Por último, desarrollan un Plan de Mejora para la motivación, donde destacan } \\
\text { los ABP (Aprendizajes Basados en Proyectos) y proyectos de recreos activos. }\end{array}$ \\
\hline
\end{tabular}




\begin{tabular}{|c|c|c|c|c|c|}
\hline $\begin{array}{l}\text { Garcés } \\
\text { Delgado, } \\
\text { Santana } \\
\text { Vega y } \\
\text { Feliciano } \\
\text { García }\end{array}$ & 2020 & $\begin{array}{l}\text { Tenerife, } \\
\text { España }\end{array}$ & $\begin{array}{l}\text { Proyectos de } \\
\text { vida en } \\
\text { adolescentes en } \\
\text { riesgo de } \\
\text { exclusión social }\end{array}$ & $\begin{array}{l}\text { Analizar cómo las variables contextuales inciden en } \\
\text { el proceso de construcción del proyecto vital de } \\
\text { adolescentes en riesgo de exclusión }\end{array}$ & $\begin{array}{l}\text { Se ha constatado en el presente estudio que estos menores en riesgo de exclusión social, } \\
\text { debido a ciertas variables contextuales como sus dificultades económicas, sus condiciones } \\
\text { de vida, su desarrollo emocional, intelectual y social deficientes, etc., se encuentran con } \\
\text { "baches" a la hora de construir su proyecto vital, puesto que presentan expectativas } \\
\text { educativas y laborales muy limitadas, no se imponen metas ni objetivos, toman decisiones } \\
\text { sin razonar sobre ellas, presentan una conducta social conflictiva, el rol social que escogen } \\
\text { no es el idóneo, y son personas impulsivas en sus actos. }\end{array}$ \\
\hline
\end{tabular}

Hadjab 2017 Granada, Las nuevas Comprobar que la progresiva infantilización de las Boudiaf España generaciones de migraciones, y su creciente explotación laboral y personas sexual, se debe a la falta de expectativas, a la quiebra menores de los sistemas de dependencia de los países de migrantes origen y a los conflictos bélicos.

Analizar y visibilizar a esta nueva generación de personas menores nigerianas explotadas sexualmente. Paliar la carencia de la literatura en dicha materia y profundizar en las realidades vividas por niñas migrantes nigerianas.
A medida que se fue avanzando en dicha investigación, se encontró con el problema añadido de la complejidad de los diferentes perfiles de este colectivo, además de muy vulnerable, estaba constituido en gran parte por niñas, lo que permite afirmar que se está produciendo una feminización creciente de menores migrantes víctimas de trata de seres humanos.

Las nuevas generaciones de personas migrantes son una respuesta y una consecuencia del sistema devastador del capitalismo que, a menudo, se disfraza con los atuendos coloniales e imperialistas. Las personas menores se erigen en nuevos actores migratorios.

\begin{tabular}{|c|c|c|c|}
\hline $\begin{array}{l}\text { Morales } \\
\text { Durán }\end{array}$ & 2018 & $\begin{array}{l}\text { Tenerife, } \\
\text { España }\end{array}$ & $\begin{array}{l}\text { Habilidades } \\
\text { sociales } \\
\text { menores } \\
\text { riesgo } \\
\text { exclusión soc }\end{array}$ \\
\hline
\end{tabular}

\section{Rodríguez 2016 Granada, Chicos}

García España marroquíes

buscando

futuro:

experiencia de

migrar, entre la

violencia

estructural y las

violencias

cotidianas
Investigar las Habilidades Sociales (HHSS) de los/as menores en riesgo de exclusión social del Centro de Atención Integral de Infancia y Familia de Aldeas Infantiles de La Laguna (CIIF).

Investigar sobre las experiencias de chicos marroquíes en distintas etapas de su proceso migratorio autónomo entre Marruecos y España, para conocer las relaciones entre la violencia estructural y las violencias cotidianas que han vivido.
Los alumnos y alumnas de esta investigación presentan un manejo adecuado de las Habilidades Sociales básicas. No obstante, debido a la situación de riesgo en la que se encuentran, condicionan dicho manejo. Sin embargo, los profesionales del centro se encargan de que estas habilidades vayan mejorando.

Gran parte de los menores que migran de forma autónoma sufren violencia, abusos, explotación, accidentes y experiencias traumáticas, como la muerte de amigos y compañeros de viaje. Violencias y estresores que tienen efectos en su salud emocional, sin recibir la adecuada atención psicológica que necesitan por no encontrarse, a menudo, preparados los sistemas sanitarios y de protección a la infancia.

Para permitir una inclusión plena de estos menores, habría que garantizar el derecho a un permiso de residencia y trabajo para todos los menores migrantes no acompañados y permitir que este se extienda más allá de los 18 años de edad.

Se refleja la necesidad de continuar y profundizar estas investigaciones para conocer la realidad de la situación y realizar mejores y más efectivas intervenciones. 


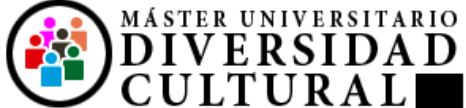

$\begin{array}{llll}\text { Rodríguez 2019 } & \text { Tenerife, } & \text { Rendimiento } & \\ \text { Rodríguez } & \text { España } & \begin{array}{ll}\text { académico } \\ \text { y Guzmán }\end{array} & \text { de } \\ \text { Rosquete } & & \begin{array}{l}\text { adolescentes } \\ \text { declarados }\end{array} & \text { en } \\ & \text { situación } & \text { de } \\ & \text { riesgo } & \\ & & & \end{array}$

Analizar las relaciones entre variables individuales y sociofamiliares en estudiantes de la E.S.O. declarados en situación de riesgo, con bajo y normal rendimiento

Identificar las diferencias que se producen en las variables analizadas en función del rendimiento académico
Esta investigación muestra cómo los alumnos y las alumnas en riesgo de exclusión social presentan diferencias significativas tanto en las variables individuales estudiadas (objetivos académicos, apoyo afectivo de la familia y percepción de lo que provoca su rendimiento académico), como en las variables sociofamiliares, dependiendo de si poseen un rendimiento académico bajo o normal.

Por otro lado, se destaca que el alumnado con un rendimiento normal se sentían más apoyados por sus familias que el alumnado con un rendimiento bajo, así como la presencia de estabilidad laboral, estudios universitarios y mayores expectativas académicas por parte de sus familias. Esto determina que la estabilidad laboral, los estudios y las expectativas académicas de los padres de los niños/as influyen significativamente en el éxito o fracaso escolar de estos.

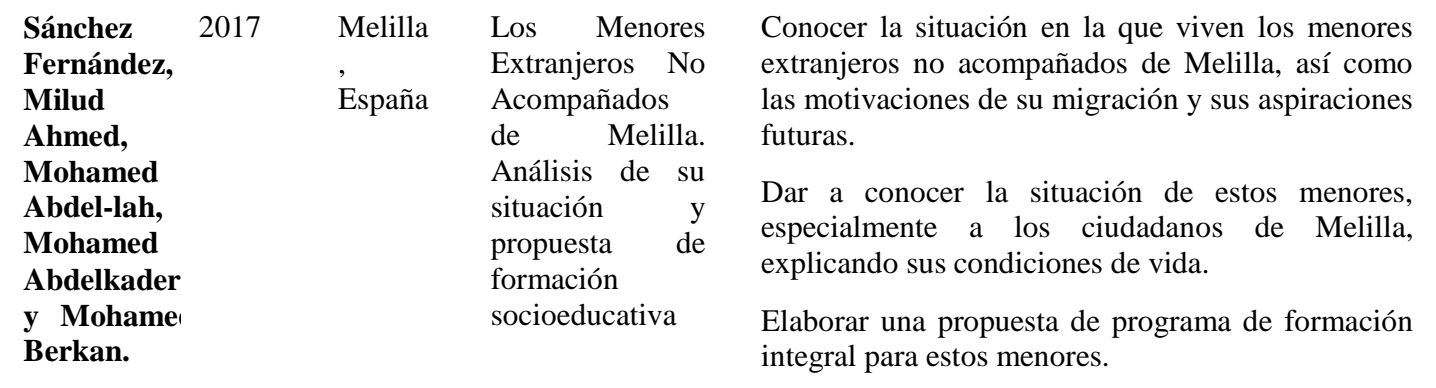

Tras el estudio realizado, se comprueba la principal característica de este colectivo, siendo esta la exclusión y marginación socioeducativa. Los ciudadanos/as de Melilla los percibe como peligrosos, teniéndoles miedo $\mathrm{y}$, por lo tanto, mostrando un rechazo mayoritario hacia estos menores. Por otro lado, este colectivo alberga un sentimiento de desprotección por parte de las instituciones y las leyes, opinando que son excluidos de la sociedad. Además, se ha comprobado la falta de medios materiales, así como de personal cualificado, y de los cuidados necesarios, que ofrecen las instituciones encargadas de su cuidado y protección hacia estos menores. Se hace hincapié en explicar a la ciudadanía melillense lo que a este colectivo los motiva a emigrar, siendo la búsqueda de una vida mejor, y la necesidad de hacerlos/as sentir parte de nuestra sociedad melillense con el fin de evitar las valoraciones negativas, la discriminación y el rechazo hacia estos. La intervención y formación socioeducativa mejora su integración, por lo que se hace necesaria.

Para responder al segundo objetivo, los programas de intervención llevados a cabo con menores, se presenta la Tabla 2, en la que se detalla el autor/es, año, lugar de estudio, nombre del programa, los objetivos planteados, la muestra utilizada en el estudio, los instrumentos de medida, duración del programa y los resultados más importantes. 


\section{UNIVERSIDAD \\ DE GRANADA}

Tabla 2.

Revisión de estudios sobre programas de intervención con menores en riesgo de exclusión social.

\begin{tabular}{|c|c|c|c|c|c|c|c|c|}
\hline Autor & Año & Lugar & $\begin{array}{c}\text { Nombre del } \\
\text { programa }\end{array}$ & Objetivos & $\mathbf{N}$ & $\begin{array}{l}\text { Instru- } \\
\text { mentos }\end{array}$ & Duración & Resultados más relevantes \\
\hline Besada Agra & 2017 & $\begin{array}{l}\text { Galicia, } \\
\text { España }\end{array}$ & $\begin{array}{l}\text { Programa de } \\
\text { Educación y Apoyo } \\
\text { Familiar }\end{array}$ & $\begin{array}{l}\text { Detectar, prevenir y superar } \\
\text { situaciones de dificultad e impulsar } \\
\text { procesos de cambio en las familias }\end{array}$ & $\begin{array}{c}6.708 \\
\text { familias } \\
13.428 \\
\text { menores }\end{array}$ & $\begin{array}{c}\text { Entrevista } \\
\mathrm{s}\end{array}$ & $\begin{array}{lr}\text { Sin límite, } \\
\text { depende de las } \\
\text { necesidades de } \\
\text { cada familia }\end{array}$ & $\begin{array}{l}\text { Mejoras de las competencias familiares. } \\
\text { Descubrimiento de sus potencialidades y responsabilidades } \\
\text { durante el proceso. } \\
\text { Cronicidad de la familia en el programa durante años } \\
\text { relacionada con una evolución no favorable. } \\
\text { Falta de motivación si las familias no han solicitado el } \\
\text { programa. }\end{array}$ \\
\hline $\begin{array}{l}\text { Fernández } \\
\text { Angulo, } \\
\text { Quintanilla y } \\
\text { Giménez }\end{array}$ & 2016 & $\begin{array}{l}\text { Valencia, } \\
\text { España }\end{array}$ & $\begin{array}{l}\text { Dialogando sobre } \\
\text { las emociones }\end{array}$ & $\begin{array}{l}\text { Fomentar el conocimiento y la } \\
\text { regulación emocional }\end{array}$ & 14 & $\begin{array}{l}\text { TEC, } \\
\text { EQi:YV, } \\
\text { ERQ-CA, } \\
\text { EI }\end{array}$ & 6 meses & $\begin{array}{l}\text { Mejora significativa en la mayoría de las dimensiones de la } \\
\text { competencia emocional. } \\
\text { No hubo diferencias significativas según la procedencia de } \\
\text { los sujetos. }\end{array}$ \\
\hline $\begin{array}{l}\text { Grau Vidal, } \\
\text { Sancho } \\
\text { Álvarez }\end{array}$ & 2015 & $\begin{array}{l}\text { Valencia, } \\
\text { España }\end{array}$ & $\begin{array}{l}\text { ProInfancia Save } \\
\text { the Children }\end{array}$ & $\begin{array}{l}\text { Mejorar la convivencia escolar y el } \\
\text { clima social en un contexto de } \\
\text { pobreza infantil } \\
\text { Prevenir la posible dificultad social } \\
\text { que esté provocando dicha } \\
\text { situación de vulnerabilidad }\end{array}$ & 14 & $\begin{array}{l}\text { ECA, } \\
\text { FOP, CF, } \\
\text { SG, GD, } \\
\text { CC }\end{array}$ & 9 meses & Evolución positiva de la convivencia en el aula de referencia. \\
\hline
\end{tabular}




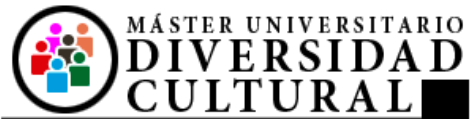

\begin{tabular}{|c|c|c|c|c|c|c|c|c|}
\hline $\begin{array}{l}\text { Hernández } \\
\text { Burgos }\end{array}$ & 2016 & Colombia & $\begin{array}{l}\text { Fomentando la } \\
\text { plenitud del } \\
\text { desarrollo para } \\
\text { la calidad de } \\
\text { vida }\end{array}$ & $\begin{array}{l}\text { Diseñar estrategias educativas y } \\
\text { de refuerzo escolar que brinden } \\
\text { herramientas para minimizar el } \\
\text { estado de vulnerabilidad de los } \\
\text { niños/as }\end{array}$ & $\begin{array}{c}\text { No } \\
\text { especificad } \\
\text { o. Se } \\
\text { trabaja con } \\
\text { un grupo } \\
\text { amplio de } \\
\text { población } \\
\text { infantil }\end{array}$ & $\begin{array}{lr}\text { IIEC, } & \\
\text { observación } & \\
\text { directa } & \text { de } \\
\text { talleres } & y \\
\text { entrevistas } & \end{array}$ & $\begin{array}{l}3 \text { meses } \\
(13 \text { sesiones })\end{array}$ & Mejora de la calidad de vida. \\
\hline $\begin{array}{l}\text { Lamoneda } \\
\text { Prieta }\end{array}$ & 2020 & $\begin{array}{l}\text { Andalucía, } \\
\text { España }\end{array}$ & $\begin{array}{l}\text { Programa bio- } \\
\text { ecológico en la } \\
\text { responsabilidad } \\
\text { y satisfacción } \\
\text { en Educación } \\
\text { Física }\end{array}$ & $\begin{array}{l}\text { Mejorar la responsabilidad } \\
\text { personal y social } \\
\text { Promover hábitos de vida } \\
\text { saludables y relaciones sociales } \\
\text { más estrechas }\end{array}$ & 120 & CREF, CASEF & 9 meses & $\begin{array}{l}\text { Mayor nivel de responsabilidad en EF en el grupo experimental } \\
\text { respecto al control. Sin embargo, no se hallaron diferencias en } \\
\text { el interés por la EF, que para ambos grupos fue satisfactoria. }\end{array}$ \\
\hline $\begin{array}{l}\text { Mata, Gómez } \\
\text { Pérez y } \\
\text { Calero }\end{array}$ & 2018 & $\begin{array}{l}\text { Granada y } \\
\text { Málaga, } \\
\text { España }\end{array}$ & $\begin{array}{l}\text { Programa de } \\
\text { Entrenamiento } \\
\text { en Habilidades } \\
\text { de Resolución } \\
\text { de Problemas } \\
\text { Interpersonales } \\
\text { para Niños }\end{array}$ & $\begin{array}{l}\text { Entrenar las habilidades de } \\
\text { resolución de problemas } \\
\text { interpersonales en niños en } \\
\text { situación de exclusión social }\end{array}$ & 61 & $\begin{array}{l}\text { ESCI, FPRTCV, } \\
\text { CHIS, WISC-IV }\end{array}$ & 9 meses & $\begin{array}{l}\text { Mejora en la resolución de conflictos y de problemas } \\
\text { interpersonales. }\end{array}$ \\
\hline
\end{tabular}


Nota. TEC: Test of Emotion Comprehension; EQi:YV: Cuestionario de Inteligencia Emocional "Emotional Quotient Inventory Youth Version"; ERQ-CA: Cuestionario de Regulación de la Emoción en la Infancia y Adolescencia; EI: escala de Inestabilidad Emocional; ECA: Escala de Clima de Aula; FOP: Fichas de Observación Participante; CF: Cuestionario Final; SG; Sociograma; GD: Grupo de Discusión; CC: Cuaderno de Campo; CREF: Cuestionario de Responsabilidad personal y social en contextos de Educación Física; CASEF: Cuestionario para el Análisis de la Satisfacción en Educación Física; EAR: Escala de Autoestima de Rosemberg; LAEA: Listado de Adjetivos para la Evaluación del Autoconcepto; CCECS: Casa y Comunidad. Escalas de Comportamiento Social; CHIS: Cuestionario de Habilidades de Interacción Social; ESCI: Evaluación de Solución de Conflictos Interpersonales; FPRTCV: Faux Pas Recognition Test, Child Version; WISC-IV: Escala de Inteligencia Wechsler para Niños-IV; IIEC: Inventario Infantil de Estresores Cotidianos.

Una vez registrados los datos mostrados en las tablas anteriores, se exponen los resultados de los mismos.

\section{RESULTADOS Y DISCUSIÓN}

En este apartado se dará respuesta a los objetivos planteados en esta investigación. Así, en relación con el primer objetivo, analizar las investigaciones que estudian la situación de los menores en riesgo de exclusión social en la Figura 7, se puede observar cómo se distribuyen los documentos según el año en el que fueron publicados.

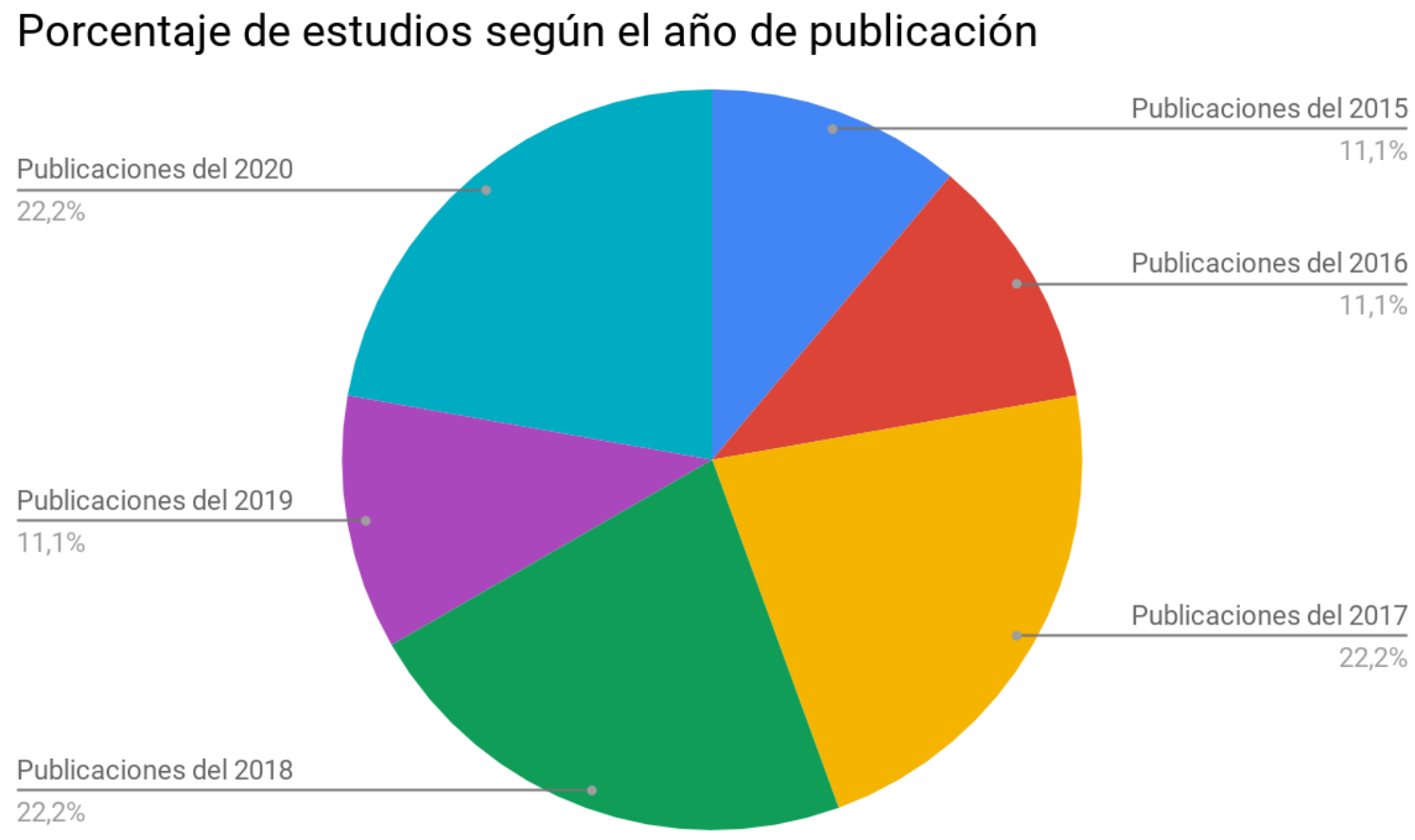

Figura 7. Porcentaje de estudios que analizan la situación de menores en riesgo de exclusión social según el año de publicación. 
Como se muestra en dicha Figura, los años en los que ha habido un mayor número de publicaciones son 2017, 2018 y 2020. Por el contrario, se ha encontrado un menor número de estudios publicados en los años 2015, 2016 y 2019. En relación con las pocas investigaciones obtenidas en la búsqueda bibliográfica sobre este tópico de trabajo, hay que incidir en la importancia de estos estudios ya que como se menciona en el Informe realizado por la Fundación Foessa (2014) España es uno de los países europeos con mayor índice de pobreza infantil. En esta línea, ya el presidente del Comité Español de Unicef en 2004 incidía en la necesidad de realizar investigaciones rigurosas sobre las necesidades básica que presentan los menores con el fin de garantizar su inclusión en la sociedad. Además, el Informe de Foessa de 2019 indica que España está atravesando por múltiples dificultades por lo que se necesitan políticas sociales para revertir esta situación.

En cuanto a los lugares en los que se han llevado a cabo estas investigaciones, los resultados obtenidos (Figura 8) muestran que es Tenerife el lugar en el que se han elaborado un mayor número de investigaciones, con un total de 4 investigaciones, seguida de la ciudad de Granada, en la que se ubican 2 investigaciones, y por último las ciudades de Sevilla y Melilla, en las que se encontró una investigación que cumpliera con todos los criterios determinados, en cada una.

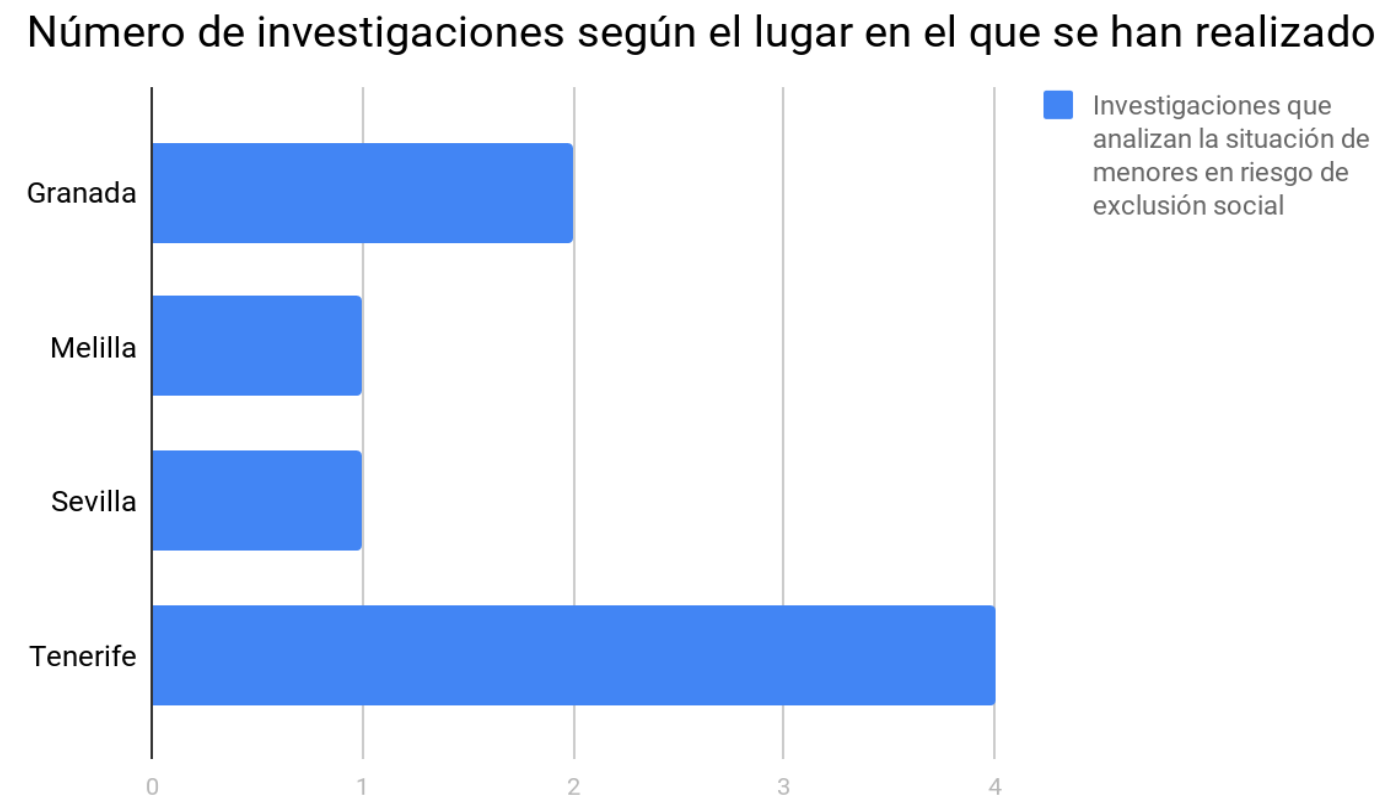

Figura 8. Número de investigaciones que analizan la situación de menores en riesgo de exclusión social en función del lugar de realización. 
Estas investigaciones, según el objetivo trabajado o la temática tratada con relación al colectivo de menores en riesgo de exclusión social, se pueden distribuir en las siguientes categorías (Figura 9): Menores Extranjeros No Acompañados, Educación, Habilidades Sociales, Pobreza infantil y vulnerabilidad de los derechos y Proyectos de vida. Todas las categorías constan de dos publicaciones, excepto la categoría de Habilidades Sociales, con una sola publicación.

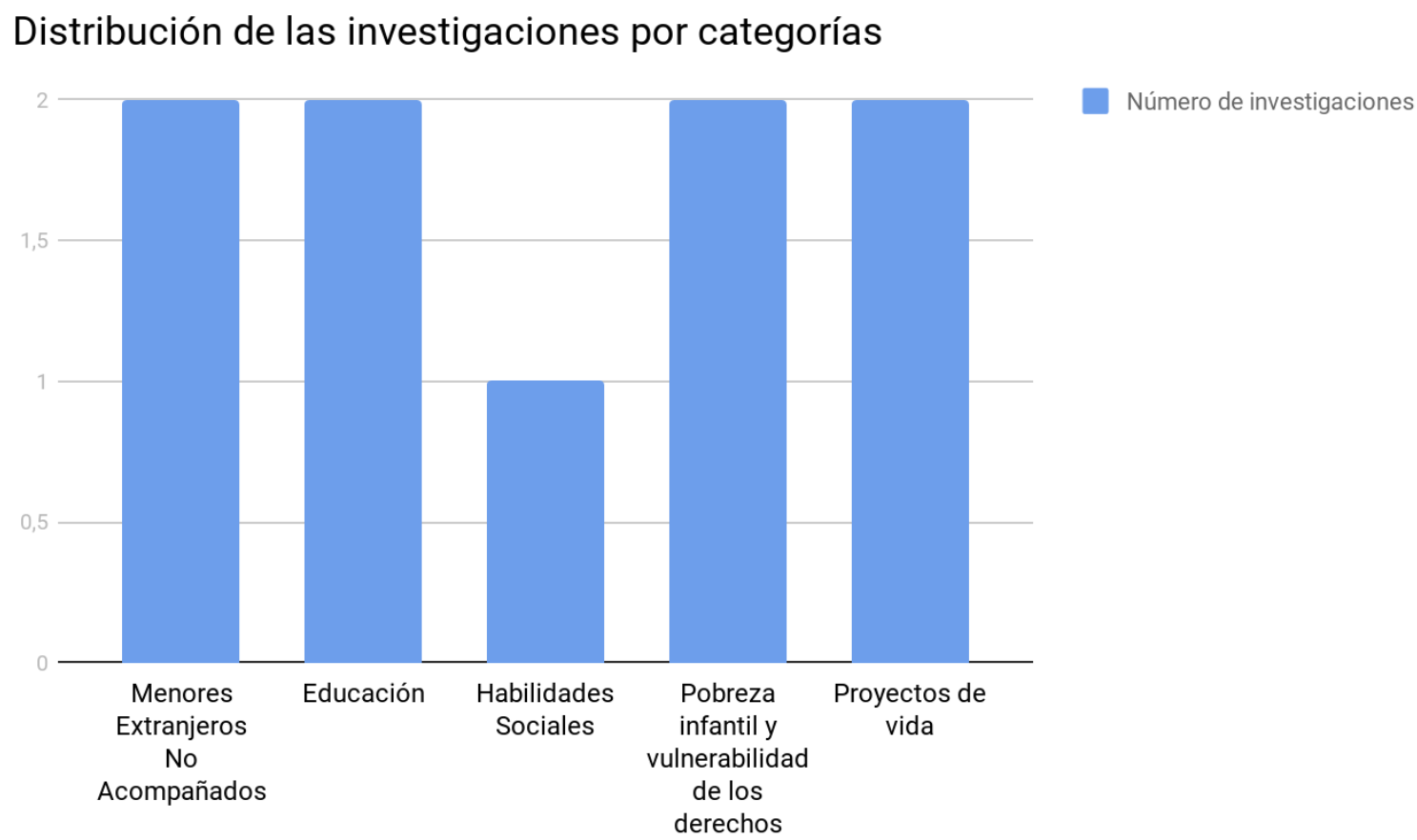

Figura 9. Distribución por categorías de las investigaciones seleccionadas que analizan la situación del colectivo de menores en riesgo de exclusión social.

A continuación, y para dar respuesta a las preguntas planteadas ¿Qué variables sociodemográficas son las más estudiadas en menores de exclusión social?, y ¿Cuáles son las variables predictoras que pueden ayudar a poner en marcha programas de intervención?, se va a realizar una descripción más amplia acerca de estas investigaciones, exponiendo algunas de sus similitudes, así como diferencias acerca de estos, y para ello, nos servirá de ayuda la clasificación por categorías. 
En cuanto a las investigaciones sobre los Menores Extranjeros No Acompañados, analizan la situación de estos menores en Melilla (Sánchez Fernández et al., 2017) y Canarias (Alonso Bello et al., 2020). En relación con la investigación llevada a cabo en Melilla pretende analizar la situación de estos menores, así como elaborar una propuesta de formación socioeducativa para este grupo de riesgo, mientras que la realizada en Canarias profundiza sobre las competencias de empleabilidad de menores inmigrantes no acompañados. Ambas investigaciones profundizan en conocer cuáles son sus motivaciones y metas de futuro. Hay que mencionar que en ambos contextos existe una alta presión migratoria y además, en Melilla, debido a su situación geopolítica (Segura et al., 2017), el número de menores extranjeros no acompañados va en aumento en los últimos años (Sánchez et al, 2017). Además, con el primer trabajo se quiere concienciar a la población melillense sobre la precaria situación de estos menores, con el objetivo de paliar esa visión y actitud tan negativa hacia ellos, y de este modo, conseguir su integración en la sociedad. Ambos trabajos comparten las características de tratarse de una investigación con una metodología cualitativa, donde se emplea la entrevista como principal instrumento de recogida de datos, y que la muestra cuenta con un total de cuatro menores extranjeros no acompañados, siendo todos ellos varones. Con respecto a los resultados, en ambos estudios, los participantes informan que el principal motivo para dejar su país es la falta de recursos económicos y la necesidad de mejorar la calidad de vida y economía de sus familias, por lo que siguen manteniendo contacto con ellas. De hecho, sus familias son su gran refuerzo, ya que los motivan a seguir avanzando y mejorar sus vidas. Como experiencias, los menores de ambos estudios destacan el sentimiento de frustración e impotencia al llegar a la ciudad de acogida y no conocer la lengua propia del lugar, ni sus claves culturales.

Comparando ambas investigaciones, en cuanto a su metodología de trabajo, cabe destacar la duración de éstas, puesto que la realizada en Canarias tuvo una duración y seguimiento de tres años, mientras que la realizada en Melilla no tuvo seguimiento a lo largo del tiempo. Por otra parte, se incide en que el estudio de Canarias contó con numerosos instrumentos, además de las entrevistas, como son las fichas de trabajo, los diarios de campo, registro de control, plan individual de emancipación e informe sobre las prácticas realizadas.

Por otro lado, lo que diferencia a la investigación realizada en Melilla es que, en esta, se llevan a cabo entrevistas hacia la población melillense, concretamente a 4 personas entre 22 y 40 años, con el fin de conocer las valoraciones y opiniones acerca de los menores 
extranjeros no acompañados, y poder, además, concienciarse acerca de la precaria situación de estos. En los datos obtenidos de estos entrevistados se comprueba que, por regla general, la ciudadanía melillense presenta valoraciones negativas hacia este colectivo, favoreciendo su exclusión y marginación socioeducativa. Estos resultados están en la línea de los de Segura et al. (2018). Además, concretan que algunos de los motivos podrían ser los prejuicios y estereotipos, lo que transmiten de ellos los medios de comunicación, el hecho de que sean desconocidos y vivan en la calle, y por ende, las apariencias desaliñadas. Todos los participantes opinan que esta imagen creada de estos menores se debe a la falta de información sobre estos y sus situaciones tan vulnerables. En esta línea, López Belmonte et al. (2018) concluyen que la llegada de los MENA puede acarrear alarma social como consecuencia de la estigmatización por los delitos e infracciones cometidas siendo difícil adaptarse a nuevos contextos. Aunque, en la investigación de López Belmonte et al. (2018) ninguno de los MENAS entrevistados realizaron conductas antisociales.

Por otro lado, todos los entrevistados están de acuerdo a la hora de afirmar que en la Ciudad Autónoma de Melilla existe una gran carencia de recursos educativos, medios materiales, recursos personales... y que los profesionales que trabajan con este colectivo no están lo suficientemente formados para llevar a cabo su labor. Estos resultados están en la línea de López Belmonte et al. (2018) que indican las carencias en las competencias de los futuros docentes en materia de interculturalidad. Aunque ante estos hallazgos hay que mencionar que la Universidad de Granada en el Campus de Melilla no solo forma a los futuros docentes en materias de interculturalidad, sino que además existe formación de posgrado, como es el Máster de Diversidad Cultural, ya que en este contexto tan multicultural es necesario no solo conocer estos temas, sino además aplicarlo a diario en el aula.

Para dar fin al análisis de este artículo, se concluye con la gran necesidad de implementar propuestas formativas socioeducativas, tanto para estos menores como para la ciudadanía. En este caso, se presenta una propuesta para ser implementada, cuya finalidad es la disminución de la inseguridad legal y personal de este colectivo, así como de su dificultad para emanciparse de las instituciones oficiales, lo cual mejorará su independencia en el ámbito social, educativo y laboral, formándolos en las competencias adecuadas para la búsqueda de empleo, para la adquisición de la lengua de destino, y de esta forma, conseguir una integración adecuada en sus lugares de destino. 
En cuanto a los resultados de la investigación en Canarias, es de gran interés conocer que los menores que fueron entrevistados contaban con habilidades para la adquisición de empleo, bastante adecuadas, lo cual favorecía que consiguieran su objetivo. Esto podría deberse a la educación recibida por parte de sus familias. Como remarcan Alonso Bello, Santana Vega y Feliciano García (2020), en concordancia con los estudios de Sala, Villalba, Jariot y Arnau (2013), aquellas personas que consiguen incorporarse en el mercado laboral de forma óptima, adquieren mejores habilidades sociales y resultan ser más adaptables que aquellos que fracasan en el ámbito laboral. Por ello, es importante enfocar adecuadamente los proyectos de inserción laboral, los cuales ayudan a mejorar su autoconcepto, autoestima, sus competencias de empleabilidad y su motivación.

Continuando con la categoría de Educación, se observan dos investigaciones: por un lado la que trata sobre el rendimiento académico del alumnado de un instituto (Rodríguez Rodríguez y Guzmán Rosquete, 2019), y por otro, la que trata aspectos como el fracaso, absentismo y abandono escolar de un instituto concreto (Fenoy Santiago, 2018). En la primera, la muestra se divide entre los discentes que poseen un bajo rendimiento académico y los que tienen un normal o buen rendimiento académico, esta distinción se realiza con el fin de comparar las correlaciones de cada uno de los grupos por separado, con las variables personales y sociofamiliares seleccionadas, como son, a groso modo: metas académicas, apoyo familiar afectivo y atribuciones causales del rendimiento académico. Ambos trabajos investigan a un colectivo de menores en riesgo de exclusión social, en el ámbito educativo, tratándose de alumnos y alumnas pertenecientes a institutos de Educación Secundaria Obligatoria.

Ambas investigaciones quieren responder a cuáles son las posibles causas que provocan el bajo rendimiento, fracaso, absentismo y abandono escolar, y descubrir las variables que influyen a este respecto. Si bien es cierto que en la investigación enfocada en profundizar acerca del fracaso, absentismo y abandono escolar, hay un mayor número de variables a estudiar, estas investigaciones comparten las siguientes variables: las metas académicas, el apoyo familiar, atribuciones causales (a la suerte, a la capacidad, al esfuerzo, al escaso esfuerzo, al profesorado, a la facilidad de las materias), situación laboral de los padres y nivel académico de los padres. Los resultados más destacables serían los siguientes:

Con relación a las metas académicas, en el estudio sobre el rendimiento escolar, el grupo con un rendimiento adecuado es el que posee mayores puntuaciones, mientras que el 
grupo de bajo rendimiento no tiene grandes expectativas académicas para ellos/as mismos/as. Teniendo en cuenta la investigación sobre fracaso, absentismo y abandono escolar, un $66 \%$ del aula con menor rendimiento y mayor porcentaje de faltas a clase opina que no continuará sus estudios una vez cumplida la mayoría de edad, mientras que el 50\% del alumnado de la clase con mayor rendimiento considera que sí continuarán sus estudios sin lugar a dudas. Se evidencia pues, que en ambos estudios existe una correlación significativa con la variable de metas académicas. En el estudio de Sánchez et al. (2017), los entrevistados respondieron que no tienen estudios, siendo muy pocos los que hacen algún curso.

El nivel educativo de los padres es una variable contrapuestas en estos artículos, aquí se observa diferencias en el rendimiento académico, se aprecia una diferencia significativa en los diferentes grupos de bajo rendimiento y normal rendimiento, siendo los padres con mayor nivel de estudios los que pertenecen al grupo de normal rendimiento. Por el contrario, en la otra investigación no existen diferencias significativas. En esta línea, según Gimeno Sacristán (2013) (cit. en Fernández-Larragueta et al... 2017) las posibilidades de éxito escolar y ascenso social son bajas para el alumnado de los sectores más desfavorecidos.

La variable situación laboral de los padres parece ser decisiva, ya que en ambos estudios, los padres del alumnado de mayor rendimiento escolar tienen una situación laboral estable. Aunque en el estudio de Caparrós y Gelabert (2020) indican que una de las variables que inciden en la salud mental de los niños es el nivel educativo de la familia. De igual modo ocurre con las atribuciones causales, ambos trabajos destacan que el alumnado con mejor rendimiento posee mayor dominio del locus de control interno, haciéndose responsables de sus actos y de sus calificaciones, eximiendo culpa a la suerte, la dificultad de la materia, los docentes, etc. Respecto a esta variable, algunas investigaciones determinan que un locus de control interno supone un factor protector en situaciones de vulnerabilidad para este colectivo (Benzies \& Mychasiuk, 2009; Ross \& Mirowsky, 2013).

Por último, obtienen una correlación entre las variables absentismo y abandono escolar, referido a los discentes menores que obtienen malas calificaciones y cuyo interés y/o preocupación por su futuro laboral es nulo, además de no sentir presión familiar ni social. Como expresa Marina (2011), el absentismo es un factor que distancia al estudiante del centro educativo, por lo que se ve necesario implementar estrategias y/o programas, ante esta situación, para que no se convierta en abandono escolar. No obstante, como estrategia ante el absentismo y el abandono escolar, está el fomento de la implicación del estudiante en el 
centro educativo, tal y como afirma en su investigación Wang et al. (citado en Castejón, 2016).

En relación a estas dos últimas variables, nivel educativo y situación laboral de los padres, Escarbajal, Sánchez y Guirao (2015), concluyen, de la misma manera que nuestra investigación, que se tratan de factores determinantes, muy influyentes en los resultados, obteniendo una correlación directa entre estas dos variables y el rendimiento académico de estos/as alumnos/as. De igual modo, Escarbajar, Sánchez y Guirao (2015), muestran cómo existe un factor relacionado con las variables anteriores, y que provocan impactos mayores en el rendimiento escolar de estos estudiantes, como son los ingresos económicos de las familias, que en su mayoría resultan ser muy escasos, lo cual se acentúa al tratarse de familias con, al menos, tres hermanos. Aunque, para evitar una visión tan negativa de cómo los recursos socioeconómicos familiares influyen en el rendimiento escolar y en el fracaso académico de este colectivo, la investigación Yin y Han (2008) concluyen que los aspectos socioafectivos pueden minimizar los problemas que conllevan el bajo nivel económico de las familias, incidiendo de forma positiva en el desarrollo integral del niño.

Los resultados obtenidos en ambas investigaciones evidencian la importancia que tiene la situación laboral y el nivel educativo de los padres de estos menores en cuanto a su rendimiento académico se refiere, puesto que, como presentan otros estudios, como los de Laparra (2006) y Spera, Wentzel y Matto (2009), los discentes cuyos padres tienen menor estabilidad laboral o se encuentran en desempleo, hacen que estos menores sean aún más vulnerables para alcanzar el éxito académico y no abandonar la escuela antes de la edad estipulada. Otro estudio que respalda estas conclusiones, es el de Córdoba, Preciado, Pérez, Carrizosa y Molina (2011), cuyo estudio iba dirigido también a alumnado de la E.S.O., pero que no se encontraban en situación de riesgo. No obstante, aún sabiendo que la situación de los menores en riesgo de exclusión social es sumamente más vulnerable que la de menores no declarados en esta situación, el bajo rendimiento de estos, así como su fracaso, absentismo y abandono escolar, comparten las mismas variables causales. Sin embargo, hay que remarcar que los menores en riesgo de exclusión social, al encontrarse en dicha situación, existe una mayor probabilidad de que estas variables causales se den con mayor frecuencia y en mayor grado.

Dando fin a esta categoría, cabe destacar que las investigaciones concluyen que aquellos estudiantes que se caracterizan por el predominio de locus de control interno, son 
aquellos que poseen un mejor rendimiento académico, por lo tanto, es imprescindible fomentar esto en aquellos con un rendimiento inferior, puesto que existen investigaciones anteriores con muestras similares, que verifican que estas personas con un locus de control interno se encuentran más capacitadas y dispuestas a cambiar su situación de riesgo a través de las acciones necesarias (Juby y Rycraft, 2004).

La categoría de Habilidades Sociales la conforma una única investigación (Morales Durán, 2018), cuya finalidad consiste en indagar acerca de las habilidades sociales que presentan los menores en riesgo de exclusión social, concretamente 23 menores con una edad correspondiente entre los 5 y los 17 años. Algunas de estas HHSS son: autoexpresión en situaciones sociales, defensa de los propios derechos como consumidor, expresión de enfado y disconformidad, decir no y cortar interacciones, hacer peticiones e iniciar interacciones positivas con el sexo opuesto.

En cuanto a los resultados de esta investigación, se concluye con la certeza de que estos menores poseen un manejo aceptable y normalizado de las habilidades sociales y la competencia social, sin embargo podrían ser mejoradas puesto que el entorno social y su situación vulnerable les obstruyen el paso hacia esta mejora. Algunas variables que podrían estar influyendo en su adquisición de HHSS, podrían ser las relaciones que se forjan con las personas que interactúan, ya sea esta un familiar, un amigo, un/a educador/a, etc.

Se destaca que los menores afirman que no actuarían del mismo modo con todas las personas, siendo más o menos asertivos en función de la persona con la que se trate. De este modo, se puede remarcar el factor personal y relacional en el desarrollo y empleabilidad de la competencia social.

Por último, se aprecia un déficit en el manejo de habilidades sociales como causa de la carencia en la adquisición propia de estas habilidades. En esta línea, Garcés-Delgado et al. (2020) en su investigación confirma que en el colectivo de adolescentes en riesgo de exclusión social existe un déficit en inteligencia emocional y habilidades sociales que dificulta su adaptación social. Pero, si los jóvenes permanecen un periodo de tiempo en el centro, algunas de estas habilidades mejoran de forma muy notoria. Un motivo para esto podría ser que la familia no desempeñara correctamente sus funciones, lo cual concordaría teniendo en cuenta la situación de vulnerabilidad en la que se encuentran estos menores. Otro motivo podría ser la influencia de sus compañeros, puesto que, siguiendo las aportaciones de 
Reolid (2015), las respuestas positivas o negativas, así como la asertividad por parte de los menores, están influenciadas por su grupo de iguales, así como por factores intrapersonales, condicionando de esta forma la toma de decisiones de estos, en cuanto a la realización adecuada, o no, de la habilidad en determinadas situaciones, aun conociendo bien esta habilidad, puesto que lo que prevalece en esta situación son sus intereses motivacionales.

La categoría Pobreza infantil y vulnerabilidad de los derechos recoge los estudios que, por un lado, tratan sobre la vulnerabilidad de los derechos humanos y la pobreza como características influyentes en este colectivo (Caparrós y Gelaber, 2015), y por otro, los que desean conocer cómo son las nuevas generaciones de menores inmigrantes (Hadjab Boudiaf, 2017). En cuanto al primer estudio, se trata de una revisión bibliográfica cuyo objetivo es visibilizar esta pobreza infantil y vulnerabilidad de los derechos humanos, y cómo influyen estos factores en la exclusión social de los menores. En cambio, la segunda investigación se basa en una metodología mixta que, en cuanto al aspecto cuantitativo, destaca el uso de datos extraídos de la aplicación informática SIME (Sistema Informático de Menores Extranjeros) del Programa de Mediación creado en 2008, con el fin de conocer los movimientos migratorios de estos menores en el periodo temporal correspondiente desde 1 de enero de 2008, al 31 de diciembre de 2014.

Una de las diferencias más destacadas de la investigación de Hadjab Boudiaf (2016) consiste en la participación de niñas, en disonancia con el resto de estudios en los que la mayoría de los menores eran chicos. Por ello, la investigadora considera que en estos años se está produciendo una feminización creciente de menores migrantes, siendo víctimas de trata de seres humanos, por lo que la situación de estas personas es mucho más vulnerable de lo que creía.

Ambas investigaciones coinciden en que la "corporatocracia" ha conseguido violar los tratados internacionales en cuanto a Derechos Humanos se refiere, y más concretamente a los de los niños, proclamando su poder imperialista basado en el dominio.

Además, sería interesante destacar el programa analizado en esta última investigación, llamado el Programa de Mayoría de Edad ( +18$)$, destinado a aquellas personas que aun habiendo cumplido la mayoría de edad, y habiendo estado tutelados por la ciudad correspondiente, tienen que abandonar su centro de acogida pero no disponen de la 
autonomía necesaria para independizarse, y necesitan aún una pequeña ayuda para lograr su integración en el ámbito social y laboral.

Terminamos con el análisis de estos estudios, con la categoría Proyectos de vida donde se encuentran las investigaciones sobre adolescentes que viven en riesgo de exclusión social (Garcés Delgado et al., 2020) y de los chicos marroquíes que buscan emigrar para encontrar una vida mejor (Rodríguez García, 2016). En los estudios destaca las situaciones precarias en las que se encontraban estos menores en su lugar de origen, al igual que ocurriera en los estudios de Sánchez Fernández et al., (2017) y de Alonso Bello et al. (2020), los cuales han sufrido situaciones de violencia, trabajos en condiciones inhumanas, necesidad de ayudar económicamente a sus familias, falta de recursos, tanto económicos como educativos, etc. Todos estos motivos hacen que estos menores no tengan otra alternativa que huir de su país en busca de un futuro mejor y de calidad, y así poder ayudar a sus familiares. En el momento en el que se encuentran en los centros de protección de menores, en ambas investigaciones los menores se sienten agradecidos por lo que se les ha otorgado y dicen ser tratados con respeto y cariño. Sin embargo, existe un pequeño porcentaje de menores que afirma haber tenido que escaparse de estos centros debido a la violencia producida hacia ellos, así como maltrato verbal y/o psicológico.

Como características comunes de los menores en riesgo de exclusión social que se han extraído del análisis de los resultados de ambos estudios, destaca que estos menores presentan unas expectativas, tanto educativas como laborales, bastante limitadas por su entorno y difusas; sus metas y objetivos autoimpuestos son deficientes, por lo que les resulta difícil planificar su futuro, además, si tienen claro su proyecto de vida, no ponen los medios necesarios para conseguir sus metas; toman decisiones sin detenerse en lo que están haciendo realmente, optando por un carácter más impulsivo a la hora de actuar; la mayoría presenta una conducta social conflictiva y el rol social que emplean no es el adecuado.

Para finalizar este apartado y para dar respuesta a la pregunta de investigación ¿qué variables sociodemográficas son las más estudiadas en menores en riesgo de exclusión social? Los resultados nos indican que el mayor número de investigaciones se centran en adolescentes, de edades comprendidas entre los 12 a 17 años, casi en su totalidad niños, de origen norteafricano, en su mayoría de Marruecos, y cuyas familias disponen de escasos recursos económicos, sociales y educativos, hasta tal punto de que solo unos pocos tenían el privilegio de escolarizarse y asistir al colegio. 
Por otro lado, respondiendo a ¿cuáles son las variables predictoras que pueden ayudar a poner en marcha programas de intervención? Las variables predictoras más destacadas y frecuentes en las investigaciones analizadas anteriormente son: elementos intra e interpersonales (interés, motivación, expectativas, relación con los iguales y el personal docente), el entorno, situación laboral precaria y bajo nivel educativo de los padres, pobres expectativas académicas de los padres hacia sus hijos, bajo apoyo familiar afectivo percibido, atribuciones causales de locus de control externo, pocas habilidades sociales y la pobreza. Todas estas variables han sido estudiadas en las investigaciones que se han analizado en este trabajo, dando como resultado una correlación directa entre estas variables y el grado de exclusión social y/o rendimiento académico. Cuánto más negativas han sido las variables anteriores, los sujetos de estos estudios han tenido un menor rendimiento académico o peor ha sido su situación de vulnerabilidad. Es por ello por lo que se debe observar muy de cerca estas variables $\mathrm{y}$, de este modo, poder implementar de forma más rápida y eficaz los programas necesarios para mejorar la calidad de vida de estos menores.

En relación con el segundo objetivo, evaluar los programas de intervención con menores en riesgo de exclusión social, los datos se muestran a continuación:

En primer lugar, se tuvo en cuenta el criterio del año de publicación de las referencias, no pudiendo ser estas anteriores a 2014. Se presenta la siguiente figura (figura 10) en la que se indica el número de estudios sobre programas de intervención de ámbito nacional, clasificándolos según el año de publicación.

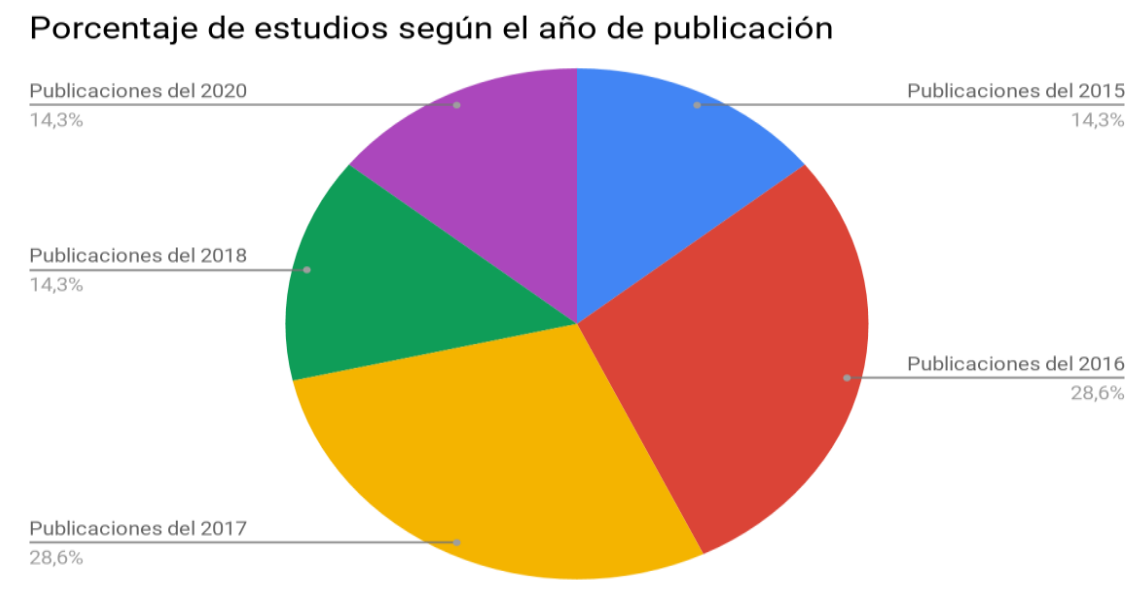

Figura 10. Porcentaje de estudios sobre programas de intervención con menores en riesgo de exclusión social según el año de publicación. 
Atendiendo al gráfico anterior, se puede observar que en 2016 y 2017 se publicaron un mayor número de estudios sobre programas de intervención con menores en riesgo de exclusión social, con un 28.6\%, siendo los años 2015, 2018 y 2020 los que menos publicaciones presentaron, con un $14.3 \%$.

Otro dato relevante, y a tener en cuenta, es la ejecución de estos programas. Se ha podido constatar multitud de propuestas, proyectos, diseños... para la intervención con este colectivo en particular, sin embargo, una gran parte de estos nunca llegaron a implementarse. En la siguiente figura (figura 11), se puede observar cuántos, de los 28 documentos, trataban sobre programas que habían sido ejecutados, y cuántos se quedaron en una propuesta:

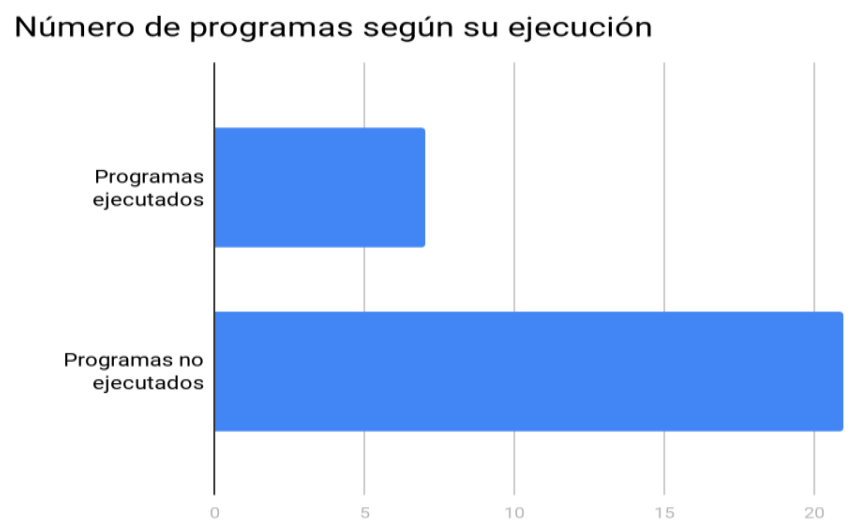

Figura 11. Número de programas de intervención con menores en riesgo de exclusión social que han sido, o no, ejecutados.

Como se observa en el gráfico anterior, sólo han sido 7 los programas ejecutados. Una posible explicación para este dato, siguiendo a Caparrós y Gelaber (2015), es que debido a la crisis económica que España ha sufrido en los últimos años ha afectado a la financiación de muchos de los programas de atención socioeducativa para menores, siendo esta situación poco favorable para años venideros por las consecuencias que la pandemia está ocasionando en la economía española.

Para finalizar, se han clasificados estos programas en diferentes categorías, en función del objetivo y/o método seleccionados en cada uno de ellos, en la siguiente figura (figura 12): 
Clasificación de programas

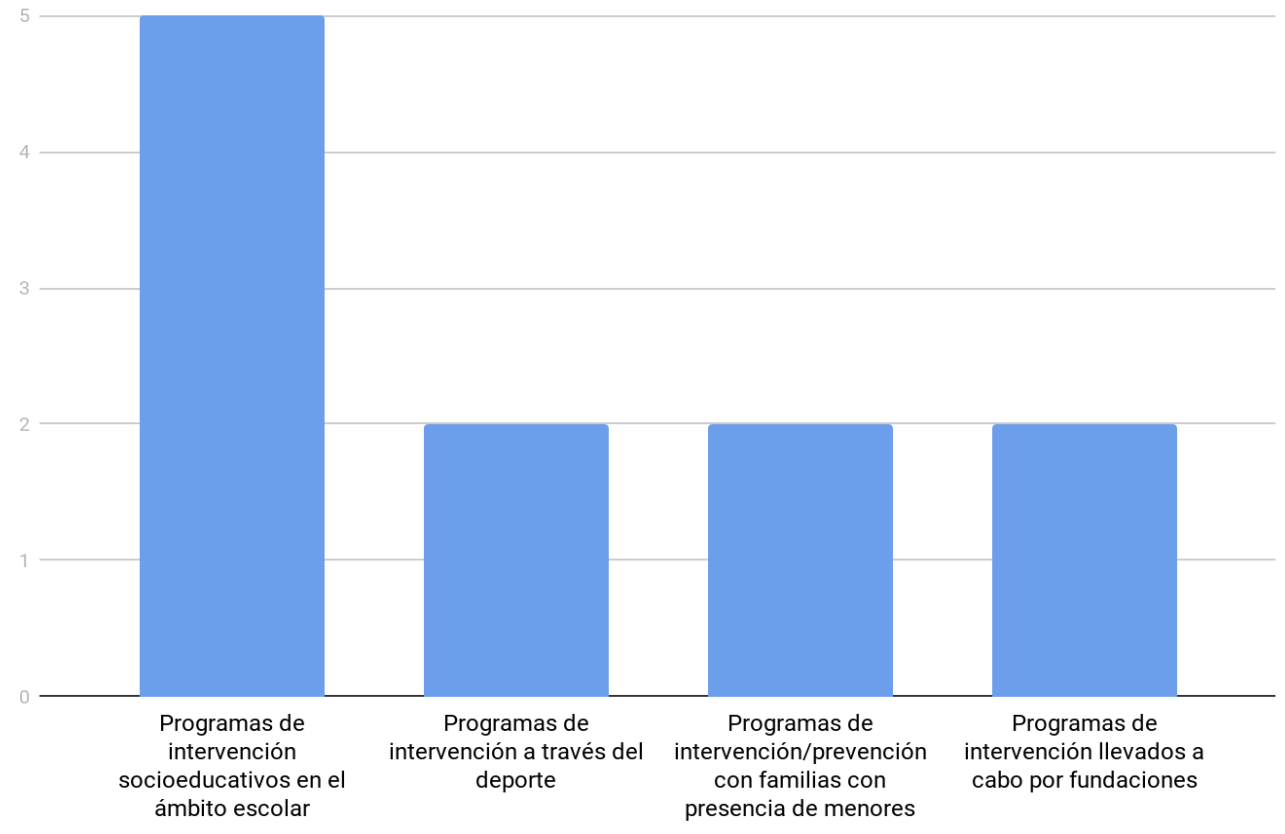

Figura 12. Clasificación de programas según el objetivo y/o método empleado.

En la Figura 12 se puede constatar cómo la mayoría de los programas se desarrollan en el ámbito educativo, y no es de extrañar, puesto que la escuela, o ya sean escenarios informales, ofrece múltiples oportunidades para crear nuevos conocimientos y habilidades a todos los niños, niñas y adolescentes, y a mayor escala a toda la comunidad educativa, así como a la sociedad, enseña y vivencia valores como el respeto, solidaridad, altruismo, empatía... Por otro lado, brinda la oportunidad de forjar verdaderos lazos de amistad, socializarse y relacionarse con todos y todas, abriendo el abanico a una enorme diversidad de personas de distinto nivel socioeconómico, distinta procedencia, etc, promoviendo así mismo una educación inclusiva siendo un escenario idóneo para llevar a cabo estos programas de intervención. En palabras de Marimuthu y Cheong (2015), la educación inclusiva es un movimiento global, compatible con el modelo social y destinado a promover la inclusión en todos los aspectos de la vida humana... Inclusión significa celebrar la diferencia, introduciendo una cultura en la que todas las personas son igualmente valoradas y todo el mundo se siente aceptado.

Pero además, los programas de atención socioeducativos no debe atender sólo a una educación inclusiva y de calidad, también debe preocuparse por destinar recursos tanto al 
ocio y tiempo libre como al acceso a la atención médica (Caparrós y Gelaber, 2015), es decir, una atención integral del menor.

No obstante, y aunque no se pueda ver bien reflejado en la figura anterior, los programas de intervención y/o prevención con menores en situación de vulnerabilidad mediante el deporte, han sido muy populares en las distintas búsquedas realizadas, sin haber sido seleccionados por motivos como textos incompletos, no haberse implementado, etc. Sin embargo, los programas deportivos han demostrado ser exitosos principalmente en la mejora de las habilidades cognitivas y de la vida social y en menor medida en las habilidades de la vida emocional (Hermens, Super, Verkooijen, y Koele, 2017). La práctica deportiva se convierte en una propuesta de desarrollo integral de cuerpo y mente, de la autoestima, el sentido ético y moral, de responsabilidad, de autonomía, de superación, de relación y aceptación de los demás, de cumplimiento de las normas de cooperación, etc., en un entorno en el que la práctica resulta altamente estimulante en sí misma (Fernández, Huete y Vélez, 2017).

A pesar de esto, queda claro tras el estudio realizado en los centros de riesgo de exclusión social en la provincia de Granada, que la Educación Física no puede ser el remedio a todos los problemas que se presentan, sino una pieza más de un complejo engranaje, que debe funcionar con perfecta sincronía, si queremos producir cambios significativos en el contexto (López, Rivera y Herencia, 2017). En esta línea, Del Sol (2013) reflexiona la importancia de la “dimensión educadora del deporte en ambientes multiculturales" (p.140).

Cabe mencionar otra categoría de programas destinados al fomento del empleo, con destinatarios jóvenes en edades comprendidas entre los 14 y los 24 años aproximadamente, en la mayoría de los casos siendo mayores de edad, por lo que tuvieron que ser descartados, pese a lo cual, estos han resultado ser muy interesantes para sus vidas futuras en la adultez. Un ejemplo de este tipo de programas es el llamado "Escuela de oficios-Semilla-", creado y llevado a cabo por la fundación "Encuentro por la Vida", cuya ubicación se encuentra en Colombia.

Para finalizar con este apartado, se van a comentar algunas similitudes, así como diferencias más destacadas, entre los siete documentos finales que se han seleccionado, para dar respuesta a la pregunta de investigación planteada ¿Cuáles son los contextos de 
intervención más frecuentes en los que se trabaja con esta población en riesgo de exclusión social? y ¿Cómo han funcionado los programas desarrollados?

En primer lugar, en cuanto a los resultados, después de implementar estos programas, han sido favorables en todos ellos, recomendando siempre seguir con dicha intervención a escalas mayores para que su impacto, en los menores en riesgo de exclusión social, sea mayor. Pero además, los programas que se lleven a cabo deberían tener una metodología rigurosa y que trabajen las necesidades básicas del colectivo de menores en riesgo (Informe Foessa, 2019), teniendo el respaldo de las administraciones y las políticas sociales españolas.

En la mayoría de los casos, estos programas se han llevado a cabo en las aulas o en ámbitos educativos, salvo en el caso del "Programa de Educación y Apoyo Familiar" (Besada Agra, 2017), ofrecido por los Servicios Sociales de Galicia, y el programa "Baloncesto y más" (Jiménez Martín, 2017). Por esto es necesario diseñar programas que tengan en cuenta el desarrollo integral de la personalidad de los menores en contextos de riesgo, desde el ámbito socieducativo hasta el área de ocio y tiempo libre y teniendo en cuenta la formación de las familias, es decir, proyectos vitales que atiendan a su contexto teniendo en cuenta los factores de riesgo y de protección de este grupo Garcés-Delgado et al., (2020). No obstante, se destaca la importancia del deporte en la implementación de programas de intervención y/o prevención de la vulnerabilidad de estos menores, con el fin de mejorar sus habilidades y competencias sociales, cognitivas, etc., de este colectivo, trabajando el respeto, los valores, el compañerismo, estilos de vida saludables... Numerosos trabajos apoyan estas aportaciones y han verificado como la actividad física y el deporte son ideales para la mejora en el desarrollo de menores y adolescentes desfavorecidos. En la misma línea, es importante remarcar cómo el uso de la actividad física y el deporte con grupos de exclusión social es ventajoso y productivo para: aumentar el autoestima, mejorar las habilidades emocionales y sociales y reducir los síntomas depresivos (Eime, Young, Harvey, Charity, \& Payne, 2013); mejorar las habilidades cognitivas, como son la fijación de metas y habilidades de autorregulación (Jonker, Elferink, \& Visscher, 2011); incidir en mejoras fisiológicas destinadas a los cambios en los neurotransmisores que muestran interrelación con una mejor situación de bienestar pleno (Lubans, Plotnikoff, \& Lubans, 2012; y mejorar las habilidades sociales, entre las cuales están la comunicación, la resolución de conflictos y la empatía (Bailey, Hillman, Arent, \& Petitpas, 2013). 
Teniendo en cuenta a los participantes de los programas, la mayoría dispone de una muestra reducida, siendo de 14, en dos casos, 15 y 61, que se corresponden con los programas "Dialogando sobre emociones" (Fernández Angulo, Quintanilla y Giménez Dasi, 2016), "ProInfancia Save the Children" (Grau Vidal y Sancho Álvarez, 2015), "Baloncesto y más" (Jiménez Martín, 2017), y "Programa de Entrenamiento en Habilidades de Resolución de Problemas Interpersonales para Niños" (Mata, Gómez Pérez y Calero, 2018), respectivamente. Por el contrario, los programas que poseen las muestras más numerosas son el "Programa de Educación y Apoyo Familiar" (Besada Agra, 2017), con una muestra de 6.708 familias, con 13.428 menores, y el "Programa bio-ecológico en la responsabilidad y satisfacción en Educación Física" (Lamoneda Prieta, 2020), con una muestra de 120 menores. Pero, además, se hace necesario partir de la premisa que no solo hay que apoyar a los menores en situación de desventaja sociocultural, sino que hay que trabajar en programas de Educación Familiar, dirigidos a personas cuyas circunstancias personales, contextuales o de origen étnico pueda suponer dificultades para el óptimo desarrollo de sus hijos (Besada Agra y Puñal, 2012).

En cuanto a la duración de estos programas, el "Programa de Educación y Apoyo Familiar" (Besada Agra, 2017), ejecutado por los Servicios Sociales, el más largo puesto que desde 1994, cuando se instauró, siempre ha estado activo y cuya duración para cada familia es distinto en función de sus necesidades, hasta pudiendo llegar a convertirse en una cronicidad y dependencia para estas familias, ya que algunas permanecen en este programas más de 5 años, y sin observar una evolución especialmente favorable. La mayoría de los programas que se desarrollan en el ámbito socioeducativo, tienen una duración de 9 meses, puesto que se corresponde a la duración del curso escolar. Para terminar, se encuentran los programas con menor duración (entre 2 y 6 meses), siendo estos, de menor a mayor duración, "Baloncesto y más" (Jiménez Martín, 2017), "Fomentando la plenitud del desarrollo para la calidad de vida" (Hernández Burgos, 2016), y "Dialogando sobre las emociones” (Fernández Angulo, Quintanilla y Giménez Dasi, 2016).

Del análisis de los programas, se puede concluir que para prevenir la inadaptación social del menor se deberán plantear programas que valoren todos los entornos sociales del niño, y que tengan en cuenta las necesidades básicas: físico-biológicas, cognitivas y socioemocionales. Así, siguiendo a Ortega-Navas (2010), los menores que viven en contextos desfavorecidos presentan carencias en algunas de estas áreas a lo largo de su desarrollo, 
manifestando más problemas escolares, más dificultades sociales, inestabilidad emocional y problemas psicológicos. Por esto, es necesario destinar recursos económicos y materiales así como desarrollar políticas sociales que vayan encaminadas a diseñar e implementar programas integrales que ayuden a la infancia a superar los problemas que conlleva las situaciones de pobreza.

Las consecuencias de sufrir pobreza infantil son muy numerosas, siendo las más destacables la exclusión, la transgeneracionalidad de la pobreza y el fracaso escolar, donde España se sitúa en los primeros puestos en cuanto a la tasa de abandono escolar temprano se refiere, con un 30\%, siendo aproximadamente el doble de la media de la Unión Europea (Caparrós y Gelabert, 2015). Por este motivo, cuando una sociedad quiere mejorar y obtener mejores resultados en el rendimiento académico de su población infantil, será necesario que ataque, de forma tajante, las desigualdades existentes, puesto que esto es la causa principal de estos enormes desniveles en el rendimiento académico (Wilkindon y Pickett, 2009:48), y más en los tiempos actuales, cuando la situación de alarma sanitaria causada por la pandemia que estamos vivenciando, arrastra consigo un mayor número de desigualdades, aumentando aún más estas situaciones de vulnerabilidad y de pobreza.

\section{CONCLUSIONES}

Para dar respuestas a las preguntas planteadas y a los objetivos de investigación, a continuación concluimos lo siguiente:

En relación a las variables sociodemográficas, las que se comentan a continuación son las más estudiadas en menores en riesgo de exclusión social (sexo, edad, procedencia, nivel socioeconómico y socioeducativo):

- Los menores extranjeros no acompañados son en su mayoría chicos, con edades comprendidas entre los 12 y 17 años, procedentes principalmente de Marruecos.

- El motivo principal de los menores en riesgo de exclusión social, que migran de su país, no es más que el de adquirir un empleo con el que poder ayudar económicamente a sus familias. Su destacada necesidad de conseguir dinero, los lleva 
a aceptar puestos de trabajo lo más rápido posible, y que en su mayoría, se caracterizan por unas condiciones precarias, dificultando su inserción educativa.

En cuanto a las variables predictoras que pueden poner en marcha los programas de intervención, se concluye:

- Las variables que más influyen en el rendimiento académico son la situación económica y laboral de los padres. Sin embargo, con el apoyo afectivo de estos se pueden minimizar sus efectos

- Las Habilidades sociales que se trabajan son autoexpresión en situaciones sociales, defensa de los propios derechos como consumidor, expresión de enfado y disconformidad, decir no y cortar interacciones, hacer peticiones e iniciar interacciones positivas con el sexo opuesto. Estos menores presentaron, en un principio, dificultades en el uso de estas, que fue mejorando conforme se desarrollaba el curso escolar.

- La pobreza infantil llega a ocasionar vulnerabilidad de los derechos humanos, exclusión, la transgeneracionalidad de la pobreza y el fracaso escolar. Esto hace necesario dedicar más recursos económicos y sociales para paliar estas consecuencias en los menores.

- Algunas de las características más comunes en los menores migrantes son sus limitadas expectativas, tanto educativas como laborales, toman decisiones y actúan de forma impulsiva, suelen presentar una conducta social conflictiva y desempeñan un rol social equivocado.

Con respecto a los contextos de intervención más frecuentes con este colectivo, se concluye con lo siguiente:

- Son pocos los programas de intervención que llegan a ser ejecutados, quedándose, la mayor parte de estos, en propuestas o proyectos.

- Estos programas se implementan principalmente en contextos educativos. No obstante, si hablamos de propuestas o proyectos de intervención, destacan los diseñados a través del deporte. 
- Si bien los programas de intervención destinados a familias con presencia de menores, así como los implementados por fundaciones, poseen muestras más numerosas que los anteriores, estos no se dan con frecuencia.

En referencia a si estos programas ejecutados han funcionado, se concluye:

- Todos los programas que se han implementado han dado resultados positivos y han conseguido mejoras en la situación de estos menores. En general, recomiendan la continuidad de estos programas y, al ser posible, con un mayor alcance de sujetos.

Se da fin a esta revisión sistemática con algunas reflexiones con vistas de futuro, como son:

Gran parte de estas investigaciones concluyen con la necesidad de implementar programas de formación socioeducativa, así como de integración, tanto para este colectivo como para la sociedad. Coinciden, además, en la carencia de la formación profesional de las personas que trabajan de forma directa con el colectivo en riesgo de exclusión social.

Es de gran importancia conseguir que la sociedad, en general, esté más informada con respecto a estos colectivos y su situación de vulnerabilidad, así como concienciar sobre esta problemática tan actual y frecuente en los tiempos que corren.

Por tanto, se concluye en la persistente necesidad de diseñar e implementar nuevos programas de intervención y/o prevención destinados para el colectivo de los menores en riesgo de exclusión social, puesto que este colectivo parece ir incrementando, mientras que la oferta de estos programas no lo hace a la par. 


\section{REFERENCIAS BIBLIOGRÁFICAS}

Alonso Bello, E., Santana Vega, L. y Feliciano García, L. (2020). Competencias de empleabilidad de menores inmigrantes no acompañados en Canarias. Journal of new approaches in educational research, 9(1), 16-29.

Asociación Cultural Norte Joven (2000). Alternativa para jóvenes en situación de desventaja social. Madrid: Norte Joven.

Bailey, R., Hillman, C., Arent, S., \& Petitpas, A. (2013). Physical activity: An underestimated investment in human capital? Journal of Physical Activity and Health, 10, 289-308.

Ballester, L. y Figuera, P. (2000). Exclusión e inserción social. En P. Amorós, y P. Ayerbe (Eds), Intervención educativa en inadaptación social, (pp. 289-331). Madrid. Editorial Síntesis.

Besada Agra, L. (2017). El programa de educación y apoyo familiar: la intervención con familias en riesgo y/o exclusión social en el contexto de los servicios sociales en Galicia. Tesis doctoral de la Universidad de Santiago de Compostela, Galicia, España.

Besada Agra, L. y Puñal, M. E. (2012). Intervención en familias con menores en situación de riesgo. IPSE-ds, 5, 47-69.

Benzies, K., \& Mychasiuk, R. (2009). Fostering family resilience: A review of the key protective factors. Child and Family Social Work, 14(1), 103-114. doi: 10.1111/j.1365-2206.2008.00586.x

Caparrós, F. y Gelaber, M. (2015). Pobreza y vulneración de los derechos en la infancia. RES: Revista de Educación Social, 20(5), 82-91.

Córdoba Caro, L., Preciado, V., Pérez, L., Carrizosa, M., y Molina, S. (2011). Determinantes socioculturales: su relación con el rendimiento académico en alumnos de Enseñanza Secundaria Obligatoria. Revista de Investigación Educativa, 29(1), 83-96.

Castejón. J.L. (2016). Psicología y Educación: Presente y Futuro. Alicante, España: ACIPE. 
D’Angelo, O. (2000). Proyecto de vida como categoría básica de interpretación de la identidad individual y social. Revista Cubana de Psicología, 17(3), 270-275.

Del Sol, H. (2013). Menores Migrantes No Acompañados en un mundo de (des) protección. Una visión multidisciplinar: El caso español. Revista de Educación Inclusiva, 7(2), 133-157.

De Miguel, M. (2000). La evaluación de programas sociales: fundamentos y enfoques teóricos. Revista de Investigación Educativa, 18(2), 189-317.

Eime, R. M., Young, J. A., Harvey, J. T., Charity, M. J., y Payne, W. R. (2013). A systematic review of the psychological and social benefits of participation in sport for children and adolescents: informing development of a conceptual model of health through sport. International journal of behavioral nutrition and physical activity, 10(1), 98.

Escarbajal Frutos, A., Sánchez Hernández, M. y Guirao Vives, I. (2015). Factores determinantes del rendimiento académico de alumnos hijos de inmigrantes y autóctonos de origen extranjero en contextos de exclusión social. Revista sobre la infancia y la adolescencia, (9), 31-46.

Fenoy Santiago, N. (2018). Fracaso, absentismo y abandono escolar en zonas en riesgo de exclusión social: el caso del IES Sevilla en Polígono Sur. Trabajo de fin de estudios de la Universidad de Sevilla, España.

Fernández Angulo, A., Quintanilla, L. y Giménez Dasi, M. (2016). Dialogando sobre emociones con niños en riesgo de exclusión social: un estudio preliminar. Acción Psicológica, 13(1), 189-204. Recuperado de http://dx.doi.org/10.5944/ap.13.1.15787

Fernández-Larragueta, S., Fernández-Sierra, J. y Rodorigo, M. (2017). Expectativas socioeducativas de alumnas inmigrantes: escuchando sus voces. Revista de $\begin{array}{lll}\text { Investigación } \quad \text { Educativa, } & \text { 35(2), } & \text { DOI: }\end{array}$ http://dx.doi.org/10.6018/rie.35.2.257591

Fernández, J., Huete, M. y Vélez, L. (2017). Vulnerable groups at risk for sport and social exclusion. Journal of Physical Education and Sport, 17(1), pp. 312 - 326. 
Fundación Foessa (2019). VIII Informe sobre Inclusión y desarrollo social en España. Madrid: Foessa

Garcés Delgado, M., Santana Vega, L. y Feliciano García, L. (2020). Proyectos de vida en adolescentes en riesgo de exclusión social. Revista de Investigación Educativa, 38(1), 149-165.

Grau Vidal, R. y Sánchez Álvarez, C. (2015). Menores en riesgo de vulnerabilidad social: el caso de un aula de apoyo de Save the Children-Valencia. Revista Iberoamericana de Educación, 67(1), 137-150.

Hadjab Boudiaf, H. (2017). Las nuevas generaciones de personas menores migrantes. Tesis doctoral de la Universidad de Granada, España.

Hermens, N., Super, S., Verkooijen, K. T., \& Koele, M.A. (2017). A Systematic Review of Life Skill Development Through Sports Programs Serving Socially Vulnerable Youth. Research quarterly for exercise and sport. doi:10.1080 / 02701367.2017.135552.

Hernández Burgos, F. (2016). Los escenarios educativos informales como espacios de inclusión y calidad de vida de menores en situación de marginación y desplazamiento. Tesis doctoral de la Universidad de Sevilla, España.

Jiménez Martín, L. (2017). Baloncesto y Más. Programa de intervención para niños en riesgo de exclusión social, mejora de la calidad de vida a través de la práctica deportiva. Trabajo Fin de Máster de la Universidad de Valencia, España.

Jonker, L., Elferink, M. T., \& Visscher, C. (2011). The role of self-regulatory skills in sport and academic performances of elite youth athletes. Talent Development and Excellence, 3, 263-275.

Juby, C., y Rycraft, J. R. (2004). Family preservation strategies for families in poverty. Families in Society, 85(4), 581-587. doi: http://dx.doi.org/10.1606/1044-3894.1847

Lamoneda Prieto, J. (2020). Repercusiones de un programa bio-ecológico en la responsabilidad y satisfacción en educación física: un estudio de caso en contextos de exclusión social. Espiral. Cuadernos del Profesorado, 13(26), 54-63. 
Laparra, M. (2006). La construcción del empleo precario: dimensiones, causas y tendencias de la precariedad laboral. Madrid: Cáritas Española y Fundación Foessa.

López, M. L., Rivera, E. y Herencia, M. (2017). Educación Física y desigualdad social. Percepciones de los docentes en centros de riesgo de exclusión social en la zona norte de la provincia de Granada. Journal of Sport and Health Research, 9 (1), pp. 53-64.

Lubans, D. R., Plotnikoff, R. C., \& Lubans, N. J. (2012). Review: A systematic review of the impact of physical activity programs on social and emotional well-being in at-risk youth. Child and Adolescent Mental Health, 17, 2-13.

Marimuthu, S., \& Cheong, L. (2015). Inclusive Education for Social Transformation. Procedia-Social and Behavioral Sciences, 172, pp. 317-322.

Marina, J. A. (2011). El abandono escolar. Revista de la Asociación de Inspectores de Educación de España, (14), 1-5.

Martínez Iglesias, A. I. (2016). Factores de riesgo de la conducta antisocial en menores en situación de exclusión social. Tesis Doctoral de la Universidad de Madrid, España.

Mata Sierra, S., Gómez Pérez, M. M., y Calero García, M. D. (2018). Resolución de problemas interpersonales en niños en exclusión social: Valoración de un programa de entrenamiento. Revista latinoamericana de psicología, 50(2), 107-116.

Ministerio de Sanidad, Consumo y Bienestar Social (2019). Marco de la Unión Europea $(U E)$. Gobierno de España. Ministerio de Sanidad, Consumo y Bienestar Social. Recuperado de https://www.mscbs.gob.es/ssi/familiasInfancia/inclusionSocial/inclusionSocialEspana ImarcoUnionEuropea/home.htm

Moher, D., Shamseer, L., Clarke, M., Ghersi, D., Liberati, A., Petticrew, M., ... y Stewart, L. A. (2015). Preferred reporting items for systematic review and meta-analysis protocols (PRISMA-P) 2015 statement. Systematic reviews, 4(1), 1.

Mondragón, J. y Trigueros, I. (2004). Intervención con menores. Acción socioeducativa. Madrid. Ed. Narcea. 
Morales Durán, Y. (2018). Habilidades sociales de menores en riesgo de exclusión social. Trabajo Fin de Grado de la Universidad de La Laguna, Tenerife, España.

Ortega-Navas, M. C. (2010). La educación emocional y sus implicaciones en la salud. Revista Española de Orientación Psicopedagógica (REOP), 21(2), 462- 470.

Perestelo-Pérez, L. (2013). Standards on how to develop and report systematic reviews in Psychology and Health. International Journal of Clinical and Health Psychology, 13(1), 49-57.

Pérez Juste, R. (2006). Evaluación de programas educativos. Madrid: Editorial la Muralla, S.A.

Pérez, J. (2000). La evaluación de programas educativos: conceptos básicos, planteamientos generales y problemática. Revista de Investigación Educativa, 18(2), 261-287.

Reolid, V. (2015). Propuesta de un programa de intervención para la mejora de las habilidades sociales en adolescentes. Trabajo Fin de Máster de la Universidad Jaume I, Valencia, España.

Rodríguez Espinar, S., Álvarez M., Echevarría B. y Marín, M.A. (1993): Teoría y práctica de la orientación educativa. Barcelona, España: PPU Promociones y Publicaciones Universitarias.

Rodríguez García, A. (2016). Chicos marroquíes buscando su futuro: la experiencia de migrar, entre la violencia estructural y las violencias cotidianas. Tesis Doctoral de la Universidad de Granada, España.

Rodríguez Rodríguez, D. y Guzmán Rosquete, R. (2019). Rendimiento académico de adolescentes declarados en situación de riesgo. Revista de Investigación Educativa, $37(1), 147-162$.

Room, G. (1997). El concepto de exclusión social en política social. Sociales, 9(11). Recuperado de http//: www.iesam.csic.es/doctrab2/dt-0201.pdf.

Ross, C. E., \& Mirowsky, J. (2013). The sense of personal control: Social structural causes and emotional consequences. Handbook of the sociology of mental health, 369-394. 
Sala, J., Villalba, A., Jariot, M., y Arnau, L. (2013). Socialization process and social support networks of out-of-care youngsters. Children and Youth Services Review, 34(5), $1015-1023$.

Sánchez Fernández, S., Milud Ahmed, Y., Mohamed Abdel-lah, A., Mohamed Abdelkader, N. y Mohamed Berkan, N. (2017). Los Menores Extranjeros No Acompañados de Melilla. Análisis de su situación y propuesta de formación socioeducativa. Modulema, $1,121-142$.

Sánchez Ramos, J. M. (2011). Un recurso de integración social para niños/as, adolescentes y familias en situación de riesgo: los centros de día de atención a menores. Tesis doctoral de la Universidad de Granada, España.

Spera, C., Wentzel, K., y Matto, H. (2009). Parental aspirations for their children's educational attainment: relations to ethnicity, parental education, children's academic performance, and parental perceptions of school climate. Journal of Youth and Adolescence, 38, 1140-1152. doi: 10.1007/s10964-008-9314-7

Urrutia, G. y Bonfill, X. (2010). Declaración PRISMA: una propuesta para mejorar la publicación de revisiones sistemáticas y metaanálisis. Medicina clínica, 135(11), 507-511.

Valverde, J. (1993). Proceso de inadaptación social. Madrid, España: Ed. Popular.

Wilkindon, R y Pickett, K. (2009). Desigualdad. Un análisis de la (in)felicidad colectiva. Madrid, España: Turner noema.

Yin, Y., \& Han, M. (2008). Parental Contributions to Southeast Asian American Adolescents' Well-Being. Youth \& Society, 40(2), 289-306. 